\title{
Architectural traditions of Mapungubwe and Bambandyanalo (K2)
}

\author{
A MEYER AND CE CLOETE*
}

\begin{abstract}
This article is concerned with the identification of culturally significant architectural structures and features on the archaeological sites Mapungubwe and K2, two $11^{\text {th }}$ to $13^{\text {th }}$ Century AD African capitals in the current Mapungubwe Cultural Landscape World Heritage Site in the Limpopo Province, South Africa. The objective of the article is to identify the typical architectural structures and features of the two sites, based on the original archaeological field research reports of the University of Pretoria (UP) as a primary source of information, for the purposes of architectural reconstruction and educational presentation. The archaeological field reports in the Mapungubwe Archive at UP are briefly reviewed as primary sources of information. Previous archaeological research of the University on Mapungubwe and K2 since 1933 resulted in the establishment of the Mapungubwe Museum and Archive at UP in 2000 where the field records are kept, and in the current reconstruction, interpretation and presentation of the architecture of Mapungubwe and K2 for the educational displays of the Museum. Observed remains of architectural structures and features on Mapungubwe include single free-standing stonewalls; terrace stonewalls, some of which are constructed with steps; stone platforms; stone mortar blocks and mortar hollows on exposed sandstone surfaces; circular stone structures; sets of game-hollows in rock surfaces; and on both sites the remains of circular pole and daub structures varying from small granaries to larger veranda type structures; as well as evidence of palisades and stockade type kraal structures. These architectural structures and features will be reconstructed and their cultural significance explained with the application of transdisciplinary methodology in further research.
\end{abstract}

\section{Keywords}

Keywords: African, architecture, Bahananwa, circular pole and daub structures, cone on cylinder, granary, K2, Limpopo, Maleboho, Mapungubwe Cultural Landscape, World Heritage Site, Mapungubwe Hill, Mapungubwe Museum, mortar block, rondavel, Southern Terrace, stonewall, terrace, Tshivhase, verandah hut, Vhavenda.

Disciplines: Archaeology, Anthropology, Architecture, Environmental economics

\section{Mapungubwe and K2: From excavation to conservation, interpretation and presentation}

\section{Introduction}

This article is an early report of a current research project that is concerned with the reconstruction, interpretation and presentation of the architectural structures and features of the archaeological sites Mapungubwe and K2 in the Mapungubwe National Park (cf. Figure 1). This

Proff Andrie Meyer and Chris Cloete are attached to the Department of Construction Economics at the University of Pretoria. 
basically interpretative new project is intended to reconstruct and explain the excavated architectural remains and their stratigraphic context that were recorded in the previous descriptive stratigraphic field report that was published by the University of Pretoria in 1998 (Meyer 1998), and on which many of the Mapungubwe Museum displays at UP are currently based. While the archaeological sites Mapungubwe and K2 are now managed as part of the Mapungubwe National Park by SA National Parks, and information on these sites is presented to visitors at Mapungubwe, the archaeological excavation records of the sites and a substantial collection of related cultural artefacts are curated and displayed at the publicly accessible Mapungubwe Museum at UP. Consequently, the project records in the Mapungubwe Archive at UP are the basic source of information on the architecture of the sites. An objective of the current project is to first identify from those archive records the typical architectural structures and features of Mapungubwe and Bambandyanalo (generally also known as K2) to then supplement this existing archaeological information with comparable new ethnographic information on similar architecture of living local communities. The resulting data synthesis is expected to provide a trans-disciplinary basis for the reconstruction and educational requirements of the Mapungubwe Museum at the University of Pretoria and the Mapungubwe National Park.

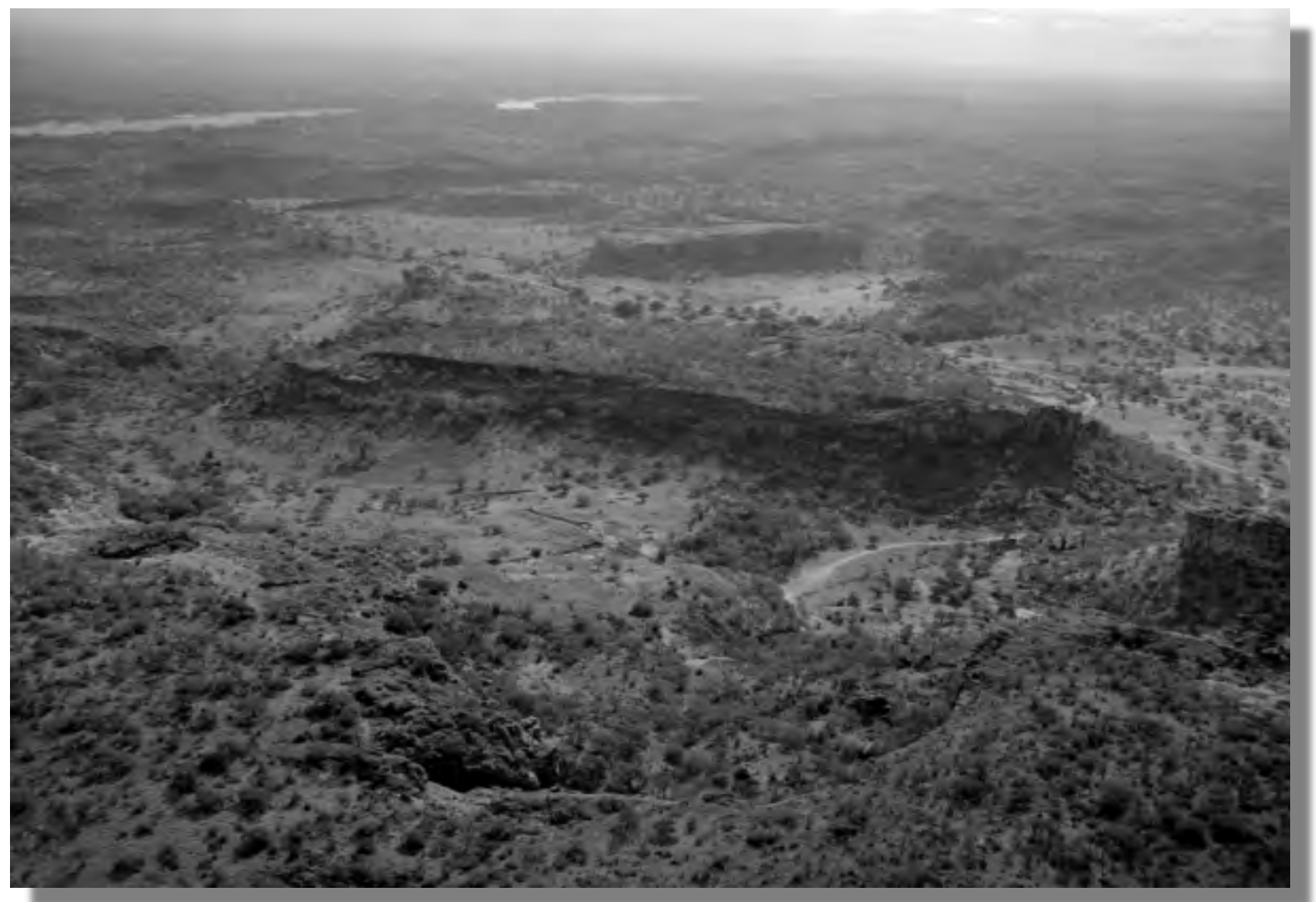

Figure 1. Aerial view of the Mapungubwe landscape from the south-west, with the site K2 situated on the raised valley floor in the foreground, the flat-topped Bambanyanalo Hill in the middle, and Mapungubwe Hill in the valley in the middle background beyond Bambandyanalo. (Meyer 1998:Figure 1.2).

\section{Mapungubwe and $K 2$ as research and heritage sites}

When the African royal settlements known as Mapungubwe and K2 on the current farm Greefswald 37 MS (cf. Figure 1) in the central Limpopo River valley were abandoned by their inhabitants after approximately three hundred years of occupation from approximately AD 1000 to 1300 , these settlements remained deserted for seven centuries before their discovery and 
rediscovery by local inhabitants between ca. 1900 and 1932. During the following seven decades from 1933 to 2003, a series of extensive and intensive archaeological excavations by the University of Pretoria and trans-disciplinary research on the human and cultural remains from the sites culminated in the proclamation of K2 and Mapungubwe as National Monuments in 1983 and 1984 respectively by the then National Monuments Council, predecessor of the current South African Heritage Resources Agency; and again as National Heritage sites by the South African Heritage Resources Agency in 2001. In 2003 UNESCO proclaimed the settlement complex of Mapungubwe and K2 and nearby archaeological sites the Mapungubwe Cultural Landscape World Heritage Site; and in 2004 SA National Parks established the new Mapungubwe National Park that includes the Mapungubwe Cultural Landscape World Heritage Site. This National Park is expected to be developed into one of southern Africa's trans-frontier parks across the boundaries of South Africa, Zimbabwe and Botswana. An important implication of these developments is that the Mapungubwe Cultural Landscape, including the architectural remains in the layers of human settlement of Mapungubwe and K2, is considered to be of particular local and international heritage value within the broader context of the southern African history, and an equally valued source of research and education information.

\section{The Mapungubwe Museum and Archive at the University of Pretoria}

The primary involvement of the University of Pretoria with the Greefswald sites since 1933 resulted in a substantial collection of cultural objects and materials from K2 and Mapungubwe and of research project documents. In 1997 a selection of cultural objects from Mapungubwe and K2, that is conserved and researched at UP, were proclaimed a National Treasure under the auspices of the then National Monuments Council. A full-scale artefact collection management programme in the Department of Anthropology and Archaeology of the University from 1998 to 1999 was followed by the transfer of the Mapungubwe archaeological collection and archive to the Department of Cultural Affairs of the University, to be presented on permanent display as the Sasol Africa Heritage Exhibition, when funding for the Mapungubwe project by the Department of Anthropology and Archaeology was discontinued. The public Mapungubwe Museum that was established at UP in 2001 then took responsibility for the Mapungubwe archaeological collection and archive; and in 2002 the Mapungubwe Museum registered the archive as an official repository that is recognized by the National Archives and Records Service of South Africa. The educational theme of Mapungubwe that was introduced into the national curriculum in 1997 was implemented into the full-time school and public education facility at the Mapungubwe Museum. The displays at the Mapungubwe Museum are currently largely based on the artefacts excavated on Mapungubwe and K2 and on the archaeological field report that was published in 1998. The Department of Cultural Affairs of the University funded and managed the Mapungubwe collection and archive under the Mapungubwe Museum from 2000 to 2007. Since then, the Department of UP Arts that was established in 2008, took responsibility for the Mapungubwe Museum with its Mapungubwe Collection and Archive, together with all the other art and heritage collections of the University. An important implication of these developments is that the UP Mapungubwe Museum and Archive curates the research documentation of the architecture of Mapungubwe and K2, which is available for further research and is a significant source of educational information to the general public. 


\section{A critique and synthesis of archaeological archive records and oral traditions}

The reconstruction of the architectural structures and features of Mapungubwe and K2 is based on the archaeological field records as the primary sources of information, subject to criteria of scientific critique, as some vague and contradictory archaeological field records are problematic. The stratification of Mapungubwe and K2 as recorded during the various excavations should be fully integrated into a comparative diagram with the use of techniques such as the Harris Matrix (Sinclair 2007). An essential source of comparative information for the reconstruction of the architecture is ethnographic analogy of which the potential is referred to in this article for research applications within the broader project. With the publication of the Greefswald archaeological field report in 1998 and the subsequent development of the displays of the Mapungubwe Museum at UP, it became clear that supplementary ethnographic information on indigenous architecture comparable to the architecture of the Mapungubwe settlement complex could be acquired from local traditions in the Limpopo region (Meyer 2007). For this purpose, the king of the Tshivhase kingdom of the Vhavenda at Sibasa, Thovhele M.P.K. Tshivhase and his Royal Council, and the king of the Bahananwa of Blouberg, Kgosi T.J. Maleboho and his Royal Council are actively supporting this ethno-archaeological interpretation of the Mapungubwe settlement complex in conjunction with the recording of their own traditions.

\section{Resourcing the Mapungubwe Archive and local oral traditions}

\section{Trans-disciplinary criteria for assessment of the primary resources of information}

As it is considered necessary to identify the typical architectural structures and features of Mapungubwe and K2 as they are recorded in different original archaeological field reports, these reports are briefly reviewed according to a selection of archaeological considerations, conditions of ethnographic analogy and internal and external critique of the information.

\section{Archaeological considerations}

As the architecture on the archaeological sites could only be investigated on-site, the relevant fieldwork records are currently the only primary sources of information for research. For the purposes of this study the use of the information in these reports are subject to the following:

1. Which field reports, that are available in the archive, contain information on the architecture of the specific sites.

2. The extent to which the architectural features as cultural remains were cleared, recorded, dated, and related to other features and cultural artefacts within the stratigraphic context during the excavation processes.

3. The extent to which the architectural structures and features in the sites were reconstructed and interpreted to understand what they actually may have looked like and what their cultural significance may have been.

4. The extent to which the archaeological remains of the architecture on the excavated sites were systematically compared to those of other sites and of the traditional architecture of living communities in the regions for the purposes of identification, reconstruction and interpretation. 
5. What the intended outcomes or uses of the information on the recorded, reconstructed and interpreted site architecture would be.

As the tangible remains of the architectural structures and features on the deserted settlement sites are the incomplete evidence of the architectural traditions of the once living inhabitants, it is necessary to supplement the archaeological records with comparable and more complete ethnographic records of similar, living peoples and their cultural traditions.

\section{Oral traditions and ethnographic analogy}

Oral traditions as a source of history are statements about remembered information from the past, that are passed on by word of mouth from one generation to the next; that as evidence from the past are for the use of historians and as such are subject to critique on aspects such as authenticity, authorship, locality and dating (Vansina 1997:12-13, 27-29, 31, 36, 54, 147). Ethnographic analogy is regarded as the use of the traditions of a living population group as an example to demonstrate the way a people may have lived in the past, subject to specific conditions according to the following criteria (Hole and Heizer 1973:311-312):

- The course of time in history is an important factor in continuity and comparison. The shorter the time lapse between the archaeological site and the living community, the better the potential for comparison.

- The socio-cultural level or structure of the inhabitants of the archaeological site and that of the living community must be fairly comparable or matched.

- The type of subsistence economy of the inhabitants of the archaeological site and of the living community should be relatively similar.

- The location of the archaeological site and of the comparable living community should not be too widely separated from each other in geographic space.

- In making inferences, language affiliation should be given low priority, as languages may differ but material aspects of culture not necessarily so.

- The level of conservatism of a community with regard to the shared cultural tradition of its members should be considered.

\section{Critique of sources of information}

Critique of oral traditions or written documents as practiced in history studies (Tosh 2006:93103) that could be applicable to reconstructing and interpreting the archaeological sites involve the following:

- External critique of the authenticity of the records.

- Internal critique of the records that is the interpretation of the record's content, including:

○ reliability of the records;

TD, 6(1), July 2010, pp. $241-270$. 

influences on the author;
$\bigcirc$ presence of bias; and
$\bigcirc$ reading sources in their context.

\section{Different descriptions and interpretations of traditional settlements and architecture}

Guidoni (1987) views architecture globally within its contexts of territory, clan, lineage, myth and power; in relation to the particular social, economic and ritual needs and activities of different societies; and within the role of architecture as political and social instrument that is subject to changes during the course of history. Similarly, the traditional architecture of African rural settlements, towns and states is considered by Denyer (1978) according to functionality including sacred, ceremonial and community buildings, defensive structures, and according to a taxonomy of house forms as well as building processes, materials and decoration. Descriptions and interpretations of the settlement sites of farming communities in southern Africa vary significantly, from an overview of southern African types of stonewall structures such as 'simple terraces and huts' and 'terrace complexes' (Summers 1971), to the interpretation of K2 and Mapungubwe in terms of state formation and the development of the Zimbabwe Culture (Pikirayi 2001), and culture signature and spatial manifestations of rain-control that are developing into centralized rain-control by the ruling elite on Mapungubwe Hill (Schoeman 2006). On a different level, the current project at the Department of Construction Economics at UP is focused on the detailed reconstruction of the architectural structures and features of Mapungubwe and K2; the site-specific associations between architectural structures and features, portable cultural objects and stratigraphic sequence; and the social significance and construction economics of the architecture as well as its significance with regard to community subsistence economy.

\section{Mapungubwe and K2 from excavation to conservation and presentation}

\section{Project research, conservation and presentation}

During the extensive and intensive excavations on K2 and Mapungubwe and studies on the excavated artefacts and materials by specialist researchers over the past 75 years, different general trends in archaeology significantly influenced the focus and method of research on Mapungubwe and $\mathrm{K} 2$, with results of varying quality and often diverse conclusions, which in turn affected the documentation and interpretation of the architectural remains on the sites. Improved research methodology in time developed into systematic excavation and stratigraphic site recording and radiocarbon dating; and studies in physical anthropology, archaeo-zoology, archaeo-botany, metallurgy and ceramic typology; all of which eventually contributed significantly to the archaeological archive records of these sites. The excavations on Mapungubwe and K2 in time revealed evidence of numerous architectural structures and elements or features, yet relatively little attention had been given to their explicit reconstruction and interpretation. A sequence of different project periods or phases can be described as early exploratory and then large-scale excavations from 1933 to 1940; limited small-scale excavations from 1950 to 1970; periodic detailed stratigraphic studies from 1970 to 1995; dedicated site and collection management, conservation and presentation to the public from ca. 1998 to current; and the current reconstruction and interpretation of the architecture of the sites and their construction economics as an integral part of the broader traditional culture systems of the inhabitants.

Early exploratory and large-scale excavations from 1933 to 1940 
The fieldwork on Mapungubwe was initiated by L. Fouché and his colleagues at UP in 1933, and was continued on behalf of UP by N. Jones and J.F. Schofield in 1934 (Fouché 1937). Three project objectives were then formulated (Jones 1937:10) as follows:

\section{The discovery of such evidence as should enable us to arrive at a certain, if probable, date for the occupation of Mapungubwe. \\ 2. The sifting of evidence for the establishment of cultural contacts with other contemporary peoples, whether indigenous or foreign.}

\section{The collection of such material as would help us to know what manner of people lived there, and to note such cultural features or peculiarities as might reveal themselves.}

The fieldwork of 1933 to 1934 included exploratory excavations with the use of contemporary archaeological excavation techniques by Fouché and his team; an area survey of stone wall ruin sites in the area by Jones; a brief ethnographic survey of traditional villages and traditional customs of local communities by G.P. Lestrade (1937) and various specialist reports on human and cultural remains at Mapungubwe and K2 and stone ruins in the area (Fouché 1937). Fouché concluded in his report (1937) that the sites were inhabited by Bantu-speaking people, apparently as the settlement remains and cultural artefacts at Mapungubwe and K2 appeared to them to be similar to the traditional settlements and personal possessions of living communities in the area at the time of their investigation. Fouché did not pursue the investigations any further as he then left the University, and Jones and Schofield withdrew from the project towards the end of 1934.

During the initial investigations of Mapungubwe by Fouché and his companions in 1933, a number of site features were noted and trial excavations were made (Fouché 1937:6-7; Plate II, III). Three access routes to the summit of Mapungubwe were noted, some of which have supporting climbing hollows cut into the cliff walls. Free-standing stonewalls that were observed above the Western Ascent (Fouché 1937:Diagram 1) and the Eastern Ascent (cf. Figure 2) were interpreted as possible defensive walls. It may be noted that the Western Ascent is referred to as the Southern Ascent by Gardner (Gardner 1963:Diagram 5). Architectural structures and features on the Southern Terrace below the Southern Ascent included substantial terrace stonewalls, a passageway, stone steps and a sequence of gravel floors that were observed and exposed in the trial excavation numbered TB1. (Cf. Figure 3 and 4).

Further records of architecture on the summit of Mapungubwe were made by Jones during general site observations and excavations in 1934 (Jones 1937). He made several fairly large test trenches in the central deposits on the summit of Mapungubwe Hill (Jones 1937:13-15; Diagram 1, 2). In his Trench JS 1, Jones encountered a stratified sequence of what he called cement pavements, midden material, occupation floor remains of red shale rubble, ash, two stone circles in an extension of the trench, and a retaining wall (Jones 1937:Plate VII, 4) that according to him was built without foundation on midden material towards the end of the occupation of the site. It should be noted that a substantial layer of habitation deposit eventually covered at least part of this terrace wall on Mapungubwe Hill. This wall is similar to the terrace stonewalls on the Southern Terrace. The deposits of Trench JS 4 is recorded by Jones to consist of the same material, and also two hut floors, one of which was structured with what Jones called a cement bench. In Trench JS 5 he found substantial midden material and a sequence of superimposed cement floors and a fireplace containing 
ash and charred marula pips. In Trench JS 6, Jones found what he described as a section of a retaining wall that did not go far in either direction and that belonged to an occupation layer just above an older cement floor. This wall may, however, be part of a circular terrace stonewall of which another section was exposed in Trench JS 1. During the summer of 1934 to 1935, the assistant Van Tonder continued with excavations in the grave area where he uncovered numerous graves, and possibly also architectural remains that were not recorded.

On the Southern Terrace, Excavation TB1 by Fouché in 1933 was extended in 1934 by Jones with his Trench JS 2(a) through the width of the Southern Terrace, in which he found sections of terrace stonewalls, and Trench JS 2(b) behind the large boulders and stonewalls where Jones uncovered substantial remains of a settlement unit consisting of different circular pole and daub type structures, stone platforms and mortar stones (Jones 1937:15-18, Diagram 1, 3). Trench JS 3 was excavated into occupation deposits above a terrace stonewall in an occupation area described as the Mahobe Site below what was called in the report the Mahobe Ascent, and of which the occupant was reputed to be Mahobe, a daughter of the last king of Mapungubwe (Jones 1937:18-19, Diagram 4).

During the excavations on Mapungubwe in 1934, explorations of the surrounding landscape resulted in the discovery of some extensive stonewalls on the hill south of Mapungubwe, named Bambandyanalo after a large, legendary rock on its slope. The field team then discovered the large midden site in a small valley to the south of Bambandyanalo Hill, also naming this site Bambandyanalo; but the site was later renamed K2 by Gardner who excavated on it from 1935 to 1940. Jones and the field team first made trial excavations in middens on K2 where they found childrens' graves. On the southern slope of Bambanyanalo Hill they also observed the remains of a solid gravel floor that could be the remains of a domestic architectural structure (Fouché 1937:19-20).

In 1935, G.A. Gardner was contracted to undertake the excavations on Mapungubwe and K2 on behalf of the University of Pretoria, which he continued during the winter months till 1940 when he was called away for military duty in World War II (cf. Gardner 1955, 1956, 1963). During 1935 to 1940 Gardner removed most of the western half of the deposits on the summit of Mapungubwe Hill in excavation blocks that were subdivided into sections. In the diary-style field-notes of his report, Gardner refers to floors and stone granary platforms, without any further description except for three general photographs of hut floors (Gardner 1963:Plate VI). Of particular interest however is his reference to and a drawing and photographs of a burnt veranda type hut, situated adjacent to the charred remains of a wooden door in a section of another structure, as well as a number of ceramic vessels (Gardner 1963:20-21; Plate VIII and IX).

Gardner's excavations on K2 from 1935 to 1940 (Gardner 1963) were basically concentrated in five areas. Firstly, Gardner made trial trenches in a smaller, separate midden that was labelled K1 and that is situated near the south-eastern side of $\mathrm{K} 2$, which he interpreted as midden material that had been washed down-slope from the main site. Secondly, he made several test pits on the north-eastern part of $\mathrm{K} 2$ where he found layers of red gravel, which he explained as hill-wash that was deposited during rain downpours. Thirdly, he made a large trial trench through the main midden of K2, where he found human skeletal remains which he considered to be the remains of Bush-Boskop (Khoi) people, apparently basing his view on the osteological identification of the human remains from the site as Bush-Boskop by Galloway (1937; 1959). Gardner recovered a 
wealth of cultural material, including potsherds, glass beads, animal bone fragments, ceramic figurines of humans and animals, all of which he considered to be part of the Khoi material culture. Fourthly, Gardner completely removed the site deposits in arbitrary excavation layers in a large excavation grid in the south-western part of K2. In this part of the site he found numerous graves containing human skeletons which he considered to be remains of Khoi people, together with numerous pits which he identified as kilns and cooking hearths of the Khoi. According to Gardner, these inhabitants of K2 lived in flimsy shelters. Fifthly, Gardner made a trial trench, Trench 2, towards the north-east of the main midden below the southern slope of Bambandyanalo, where he found abundant stratified settlement and cultural remains that he identified as settlement remains of Bantu-speaking people. In his field report (1963), Gardner, however, provided few descriptions, drawings or photographs of any architectural features on K2; but included in his report a photograph of a floor (Gardner 1963: Plate VII, 2). It may be noted that Gardner's identification of the human remains and the surrounding part of K2 as a Khoi settlement, was later disproved by the findings of other researchers.

\section{Excavations on the Southern Terrace and K2, 1950 to 1970.}

A second period or phase of excavations between 1950 and 1970 were undertaken by the then Department of Anthropology of the University of Pretoria, described in an unpublished field report by the fieldworker at the department, H.F. Sentker (Sentker 1969) and in unpublished annual reports to the National Monuments Council at that time. During 1953 to 1954, Sentker (1969) undertook limited, detailed excavations in a new excavation grid on a part of the Southern Terrace. With the assistance of staff members and students of the Department of Anthropology, he meticulously recorded and removed the upper occupation layers in several adjacent twelve feet by twelve feet excavation squares. The remains of a number of gravel floors as well as a section of a stonewall and stone platforms were uncovered and recorded in his report (Sentker 1969). During the winter seasons of 1968 to 1970, Professor H. Eloff and his students of the then new Department of Archaeology at the University of Pretoria continued with the excavation of one of the squares, E2, where they found similar gravel floors, evidence of rondavel type structures, stone platforms and stone mortar blocks. During 1968, Eloff and a team of his students excavated a small section in the wall of Gardner's excavation at K2 (cf. Figure 17) where they cut into the deposits of the large midden and the underlying dung deposits of what is believed to be the remains of a large cattle kraal (Meyer 1998: 62). It is assumed that the kraal fence had originally been a wooden stockade type of structure.

\section{Excavations at Mapungubwe and K2, 1970 to 1995}

From 1970 to 1995, a series of detailed excavations and stratigraphic studies by the Department of Archaeology that later became the Department of Anthropology and Archaeology at UP, resulted in specialist studies on the various artefacts and materials, an unpublished field report of five volumes (Eloff 1979) and various published specialist articles and post-graduate studies. During 1971 to 1973 , a research grant by the Human Sciences Research Council enabled the Department of Archaeology to undertake substantial fieldwork on Mapungubwe and K2. The objectives of these excavations (Meyer 1998:29-30) were:

1. Cultural identification according to typical cultural traits, pottery typology and chronology.

2. Reconstruction of the economy, technology and aspects of settlement.

TD, 6(1), July 2010, pp. $241-270$. 
3. Physical features and relationships of the K2 and Mapungubwe people.

4. Description of site stratification and site features; artefacts and ecofacts including metal objects, beads, artefacts of bone and ivory, stone artefacts; ceramic typology and sequence; animal remains and animal husbandry; hunting and snaring; plant remains and agriculture; collecting of food and raw materials; and the age and chronology of the Greefswald sites.

During a series of excavations undertaken by Eloff and Meyer on behalf of the University of Pretoria from 1971 to 1984 , the focus of the fieldwork included detailed stratigraphic recording of the settlement deposits at Mapungubwe and K2. The fieldwork resulted in the excavation of Square F4, H5 and K8 on the Southern Terrace; Excavation MK 1 and MK 3 on Mapungubwe Hill; and Excavation Ts 1 to Ts 6 and Excavation Rn 2 on K2. A detailed unpublished report on this fieldwork and the subsequent analysis of artefacts and other archaeological materials were submitted to the Human Sciences Research Council who funded this phase of the project (Eloff 1979). A report of these excavations with some additional fieldwork was later published (Meyer 1998). These reports contain detailed records of the excavated stratification and architectural features of Mapungubwe and K2, together with a diagram illustrating the stratified sequence of radiocarbon dates (Eloff 1979; Meyer 1998). The site settlement chronology that was reconstructed from the archaeological evidence (Eloff 1979; Meyer 1998; Vogel 1998) was summarized as four phases of occupation regarding K2 and Mapungubwe, as follows (cf. Table 1 to 3 below):

Phase I: Settlement by an Early Farming Community of which the only evidence is a small number of potsherds typologically older than AD 1000.

Phase II: The occupation of K2 and the lower layers of occupation at Mapungubwe dated ca. AD 1030 to 1220 , containing the typical circular pole and daub structures and pottery tradition of $\mathrm{K} 2$, and successions of red and light yellow siltstone gravel floors.

Phase III: The continued occupation of Mapungubwe dated AD 1220 to 1250, containing a variety of circular pole and daub structures, the prominent transition from floors made of compacted siltstone gravel to dolerite gravel floors, numerous stone platforms, sunken stone mortar blocks, and an apparent mixture of K2 pottery with an increasing quantity of a new style of pottery closely associated with the Mapungubwe cultural tradition. The terrace stonewalls on Mapungubwe Hill and the Southern Terrace can also be linked to this phase due to their stratigraphic position within the sequence of dolerite gravel floors.

Phase IV: The final occupation of Mapungubwe dated AD 1250 to 1290 , containing a succession of thin dolerite floors and cultural artefacts similar to those of Phase III, but with the addition of numerous San type bone arrowheads and arrow linkshafts in Phase IV. The occupation layers of Phase IV seem to cover or overlap at least some of the terrace stonewalling; and no circular pole and daub structures have as yet been found in Phase IV, indicating that there had been a marked decline in architectural construction at Mapungubwe at that time. The apparent stratigraphic position of at least some of the graves of humans found on Mapungubwe Hill indicate that these burials could be associated with Phase IV or alternatively with a time after Mapungubwe had been abandoned. 
During the 1990s the Department of Anatomy of the University undertook limited excavations on K2 and Mapungubwe, together with specialized studies on the human remains from these sites until the archaeological field research programme of UP regarding Mapungubwe and K2 was terminated towards 2000 .

\section{Architectural structures and features at Mapungubwe and K2}

The architectural structures and features noted in the archaeological field reports on Mapungubwe and K2 can be categorized into different types (cf. their descriptions and Figure 2 to 18 below) that can also be linked to dated settlement deposits (cf. Table 1 to 3 below).

\section{Free-standing stonewalls}

Small, isolated free-standing walls are constructed of dry-stacked stone (Figure 2). These walls are present on the summit of Mapungubwe Hill above the steep access routes to the hilltop (Fouché 1937). They presumably had a different function to that of the large free-standing enclosure stonewalls that are typical of traditional villages such as Mukumbani, the royal village, musanda, of the Tshivhase Dynasty of the Vhavenda (Van der Waal 1977; Tshikosi 2009) near Sibasa.

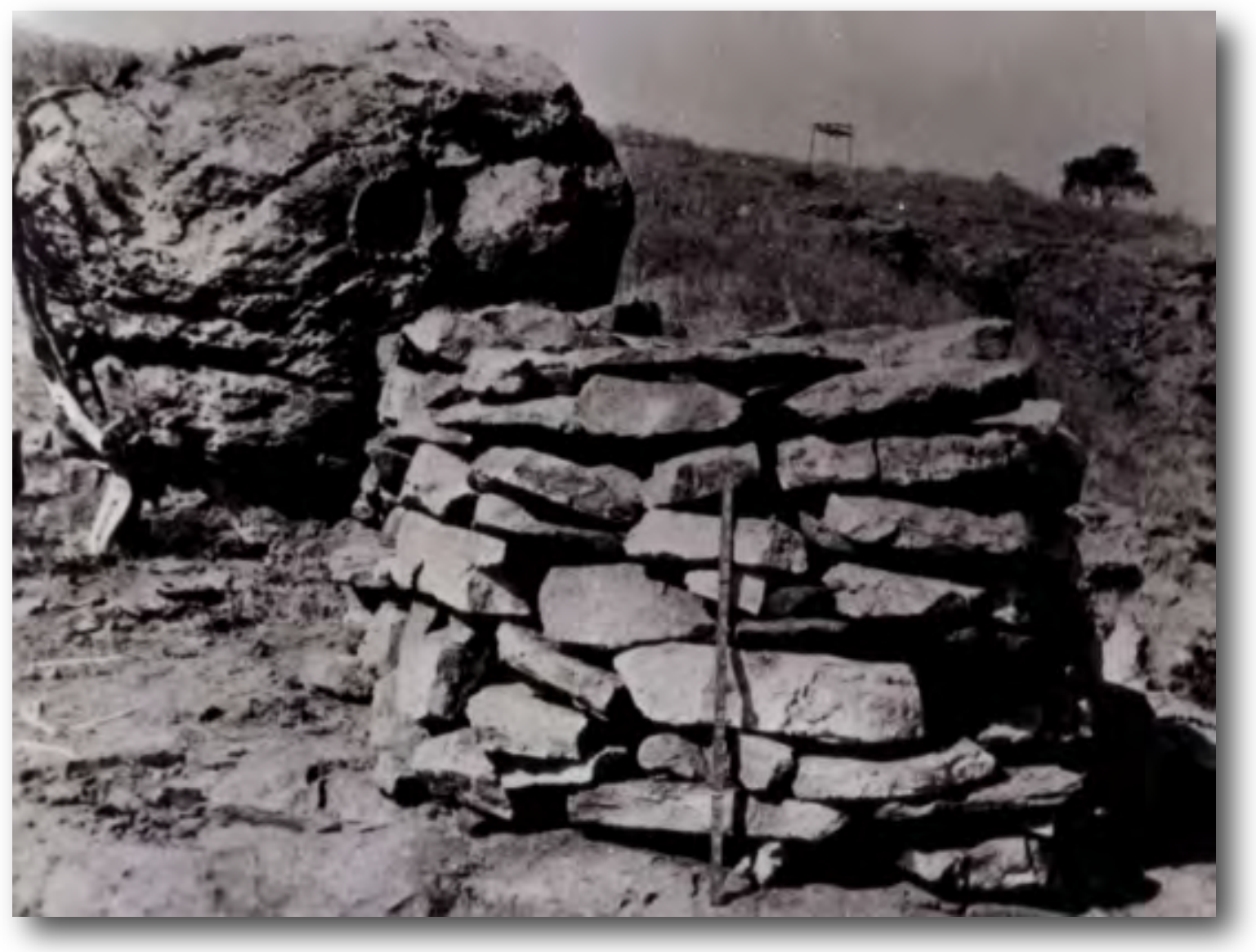

Figure 2. Free-standing stonewall above the western (southern) ascent to the summit of Mapungubwe Hill (Fouché 1937:Plate VIII, 3).

\section{Terrace or retaining stonewalls}

The terrace walls consist of a dry-stacked stonewall face with backfilling of stones and soil (Figure $3,4)$. The early excavations exposed a series of straight to curved terrace stonewalls, some with 
steps, on the Southern Terrace and a terrace stonewall on the summit of Mapungubwe Hill (Fouché 1937). Similar walls are typical of some Venda villages (Van der Waal 1977; Tshikosi 2009).

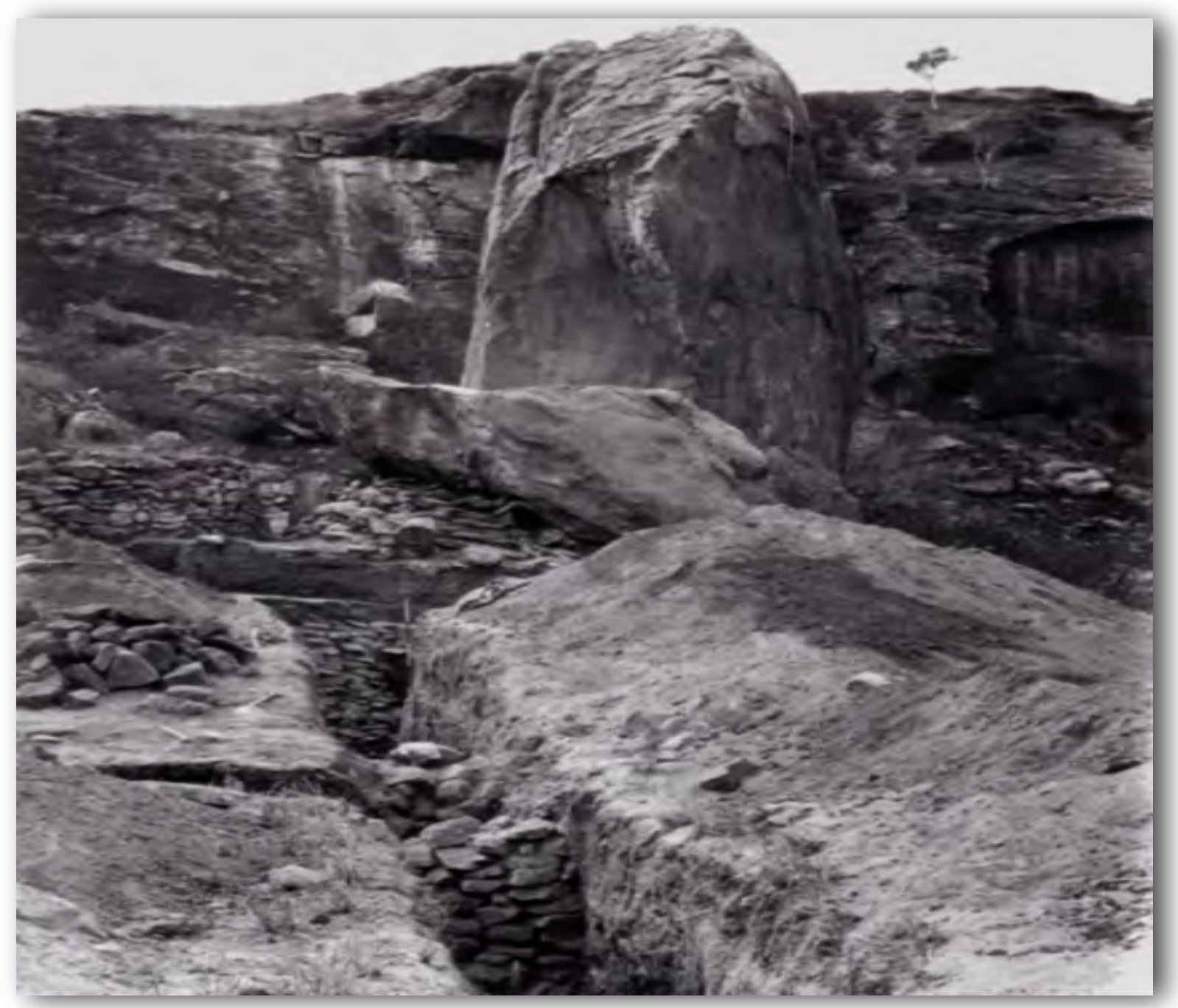

Figure 3. A series of terrace stonewalls on the Southern Terrace at Mapungubwe, exposed during the excavations of 1934 (Fouché 1937:Plate X,1). 


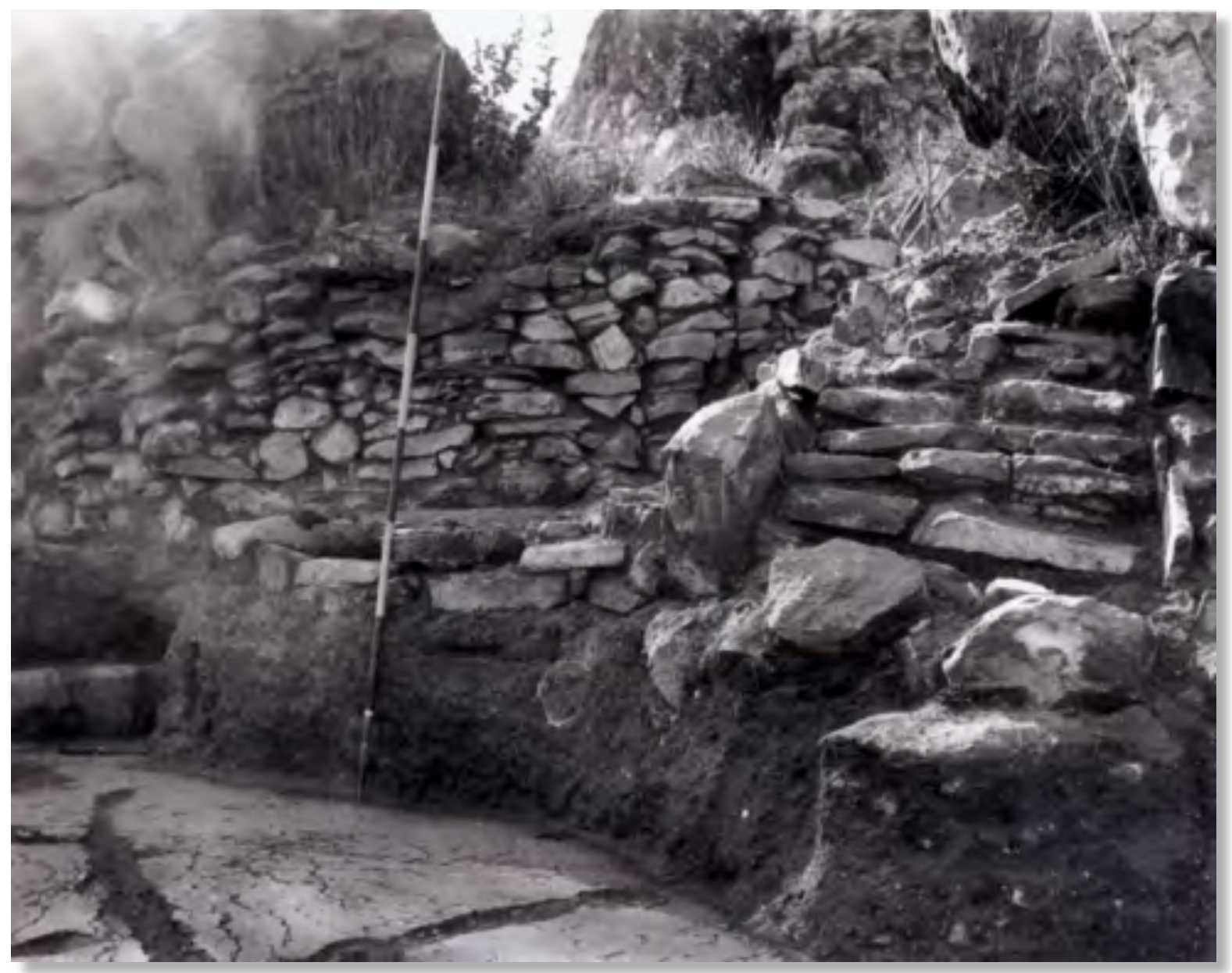

Figure 4. A terrace stonewall, constructed above a dolerite gravel floor that overlaps an underlying terrace stonewall (left); and stone steps (right) apparently belonging to a later terrace construction that was eventually partly crushed by a fallen section of the adjacent sandstone boulder (cf. similar photograph in Fouché 1937:Plate X,2).

\section{Circular stonewall bases}

The circular stonewall base type of structure consists of a double row of stones with a sandstone mortar block embedded in the wall base (cf. Figure 5). Such structures had been observed in the current site surface on the eastern part of the summit of Mapungubwe Hill, and below at the eastern foot of the Hill (Meyer 1998: 174-175). Subject to further research, this type of construction could be interpreted as the stone base of a low wall surrounding a threshing floor, and is constructed against a stone mortar block. Threshing floors are widely known, for example the Bahananwa traditionally threshed sorghum and millet on a threshing floor, seotlo, before storing the seeds in a granary basket, sešego or silo, in a granary storage hut, mothopa (Morata 2009). 


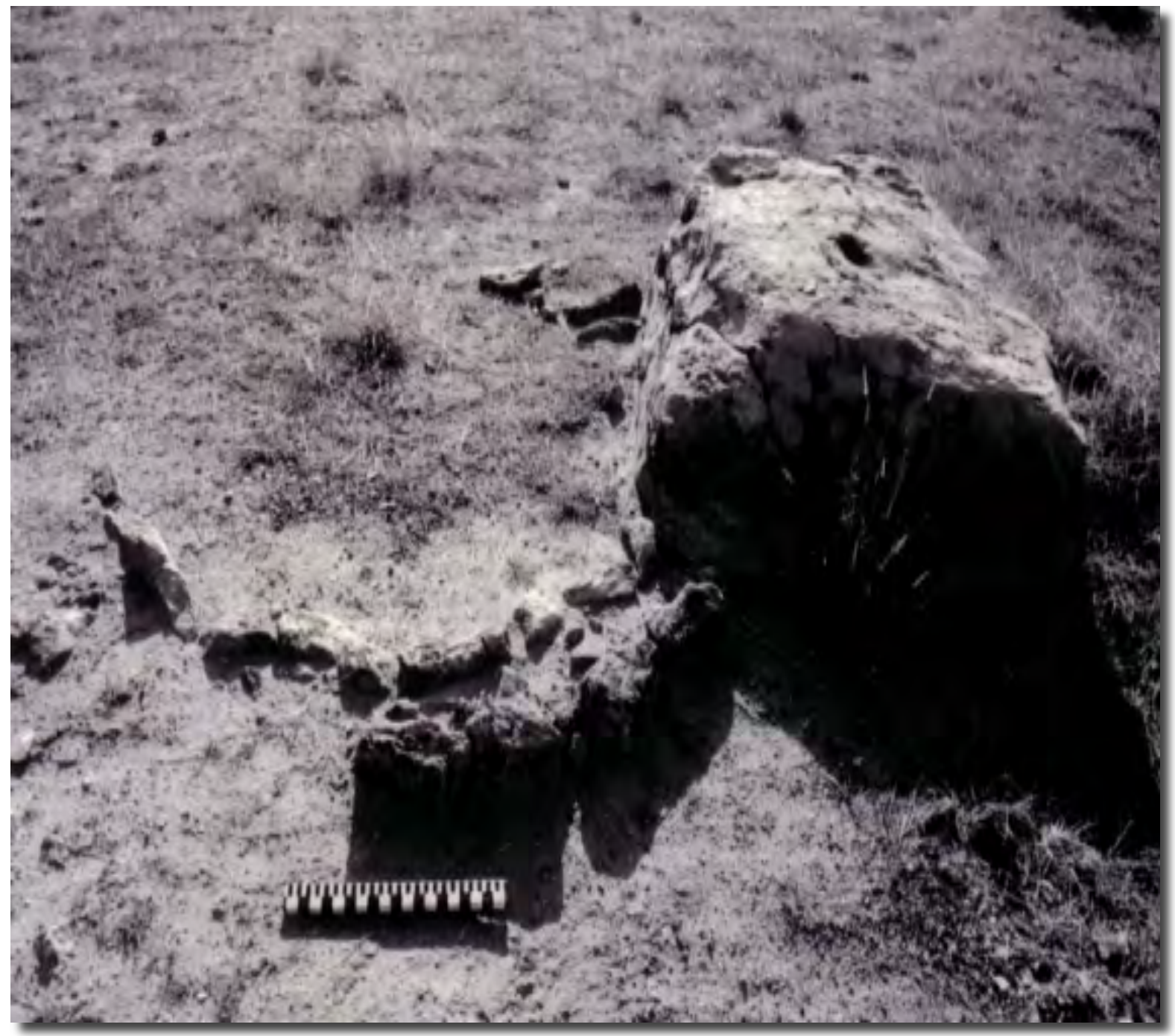

Figure 5. A semi-circular double row of stones, interpreted as the base of a low wall surrounding a possible threshing floor built against a large mortar rock, situated in the valley near the eastern foot of Mapungubwe Hill (Meyer 1998:Figure 3.107).

\section{Stone platforms}

Stone platforms are relatively small, usually circular structures that typically consist of irregular or column-shaped rocks positioned vertically in the ground, supporting flat stones (Figure 6, 7; Table 3: "stone platform"). In some cases, vertical successions of at least two stone platforms in situ were observed in layers of occupation (Fouché 1937:Plate IX, 3; Meyer 1998:123, 164). In the past, the storage basket, tshisenga, of the Vhavenda that was woven of grass and used for the storage of finger millet (eleusine), mufhoho, and beans, nawa, or various seeds was kept on a base of stones below the roof overhang or veranda of a hut (Van der Waal 1977; Tshikosi 2009). The Bahananwa traditionally use a wooden granary platform, seboya, to dry harvested grains and beans (Maleboho 2009). 


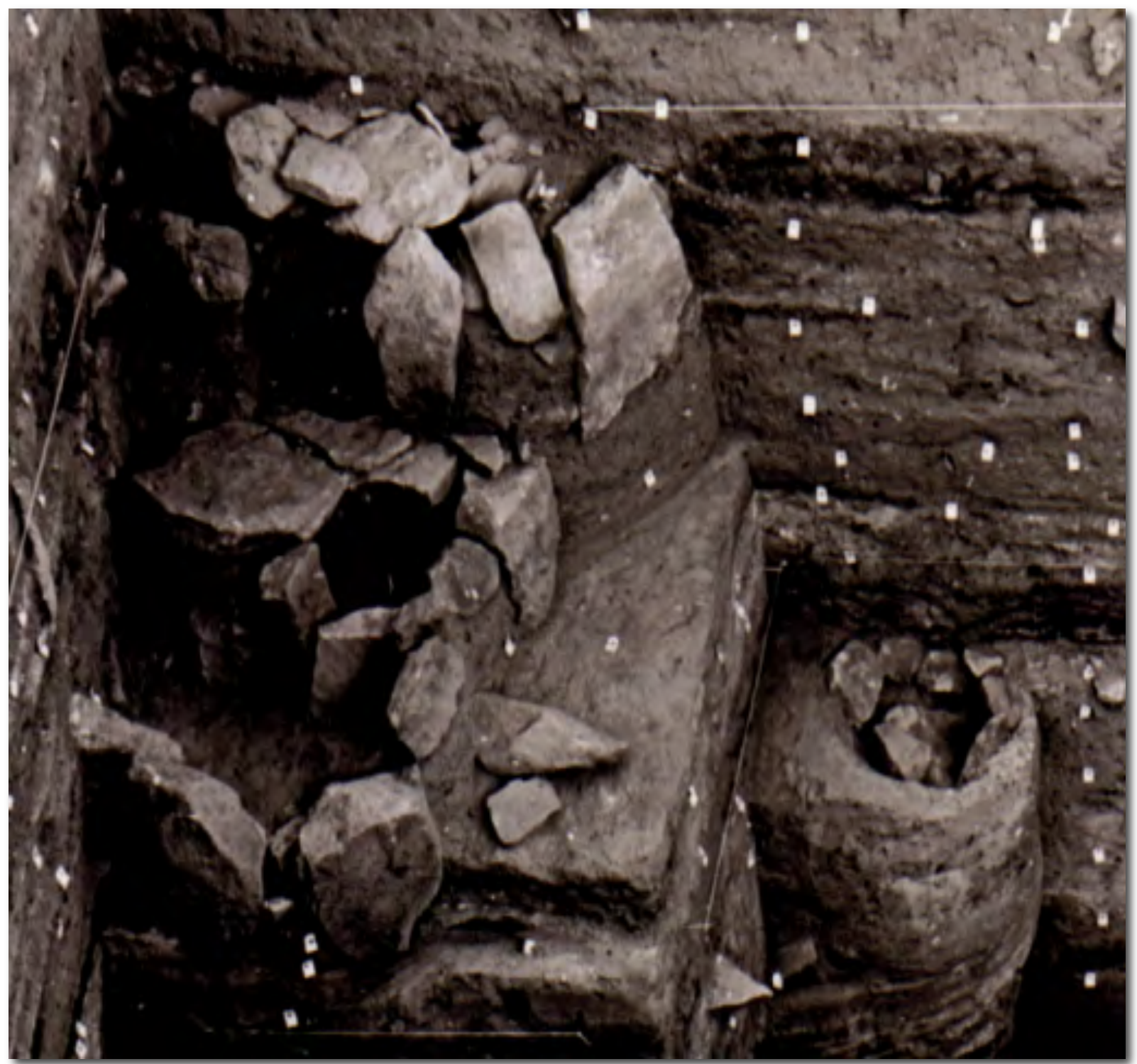

Figure 6. Succession of stone platforms in Layer 5 (top) and Layer 7 (below) in Excavation K8 on the Southern Terrace, as excavated in 1971 (cf. Meyer 1998:165, Figure 3.96). 


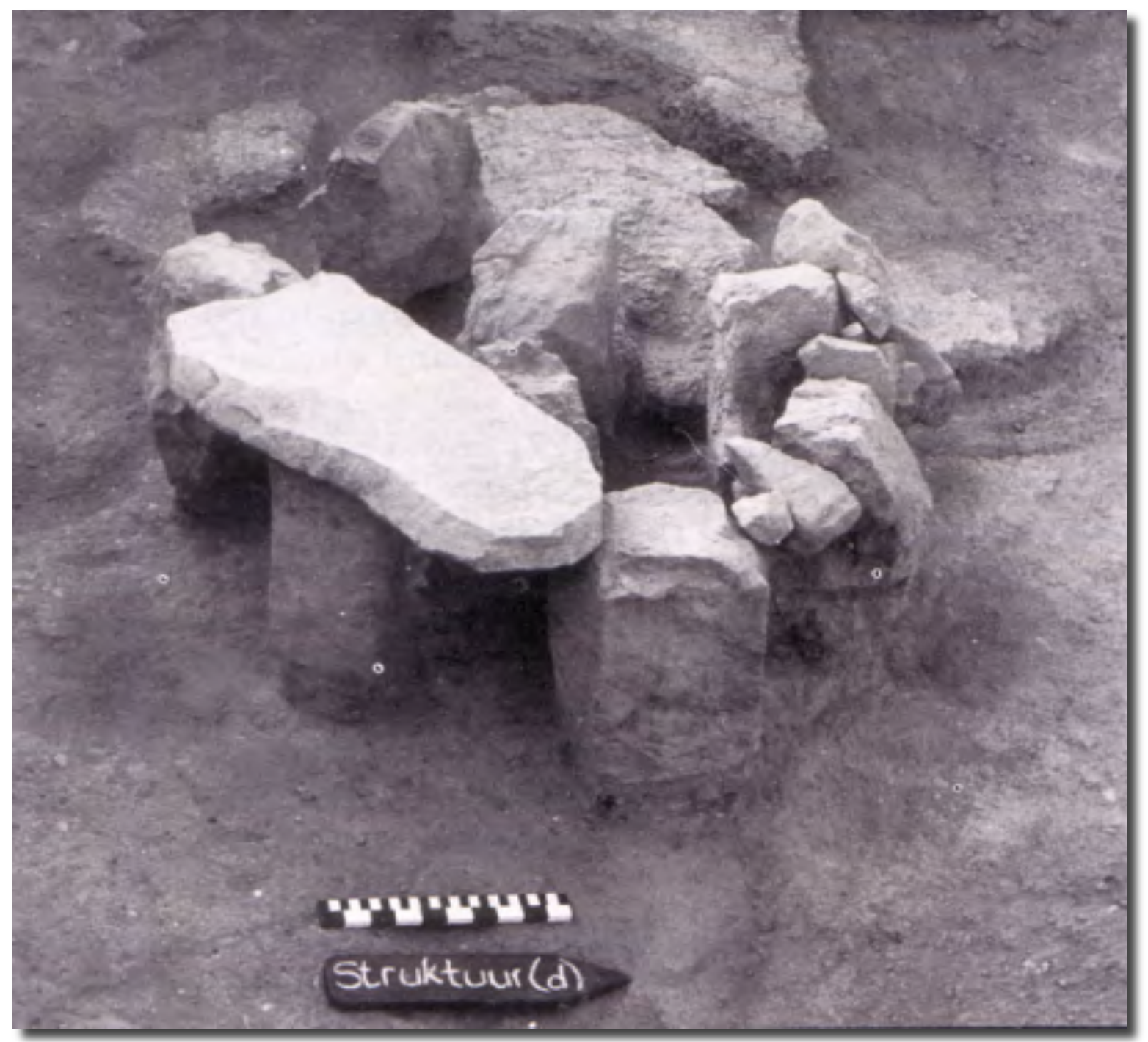

Figure 7. Stone platform consisting of columnar stones positioned vertically in a circle, some of which support a remaining flat stone (Meyer 1998:146, Figure 3.77).

\section{Stone circles}

This type of stone structure consists of a circular concentration of stones (Figure 8), two of which had been uncovered on the summit of Mapungubwe Hill in 1933 (Fouché 1937:13), one with a ceramic pot positioned on top in its middle (Van Riet Lowe 1933). 


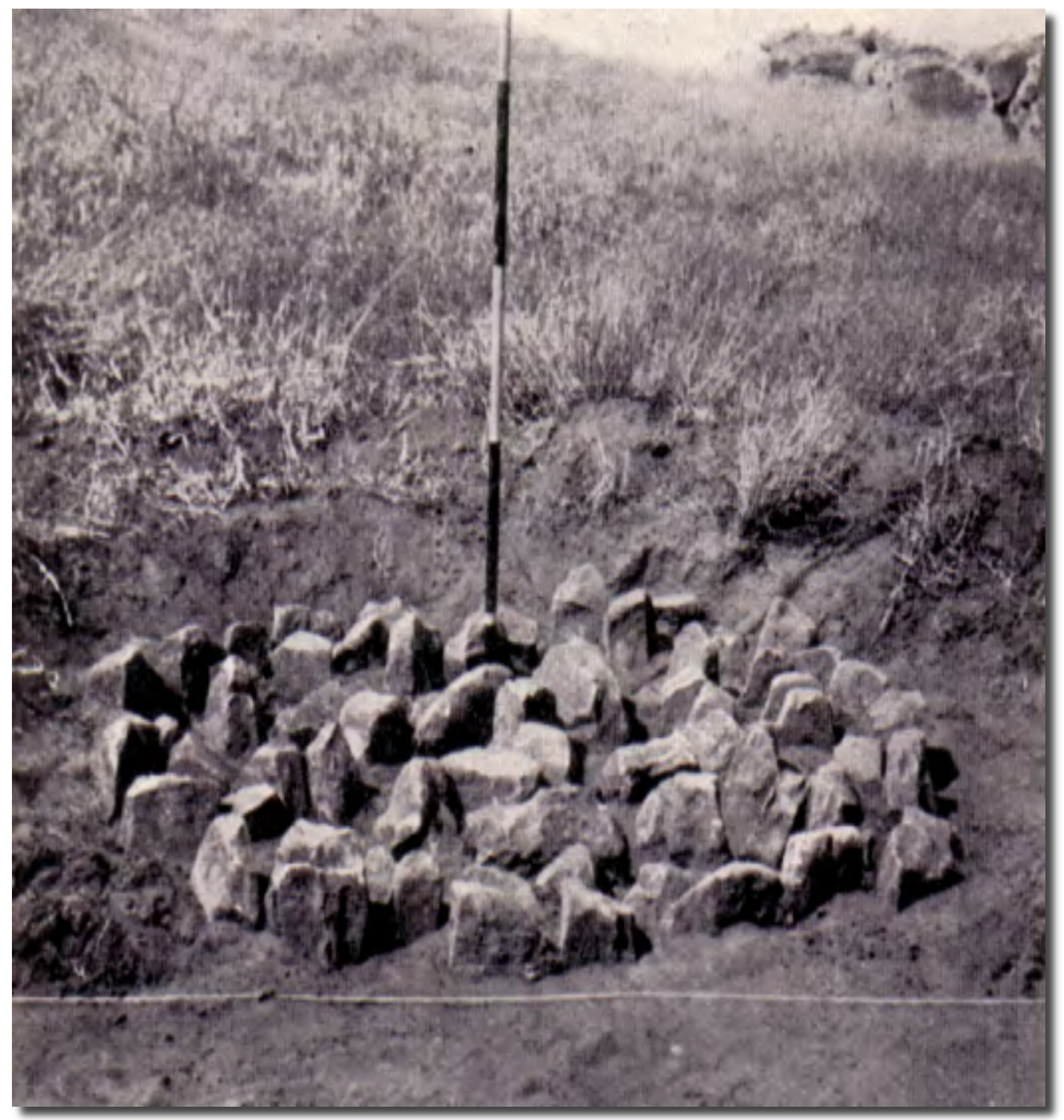

Figure 8. Stone circle observed and exposed on Mapungubwe Hill in 1933 (Fouché 1937:Plate VII,2).

\section{Vertical stones and small monoliths}

This type of structure varies from vertically positioned columnar stones typically arranged in a circle, to single monoliths (cf. Figure 9; Table 2: "Vertical stone columns"). These may be similar to the tshinari, of the Vhavenda, a small structure consisting of several sacred stones that are embedded in the floor or in a low platform, where beer or water is sacrificed to the ancestors, and where they often keep a flower known by them as thidigwane in the centre of the stone circles (Tshikhosi 2009; cf. Van der Waal 1977). The Bahananwa have similar structures (Morata 2009). 


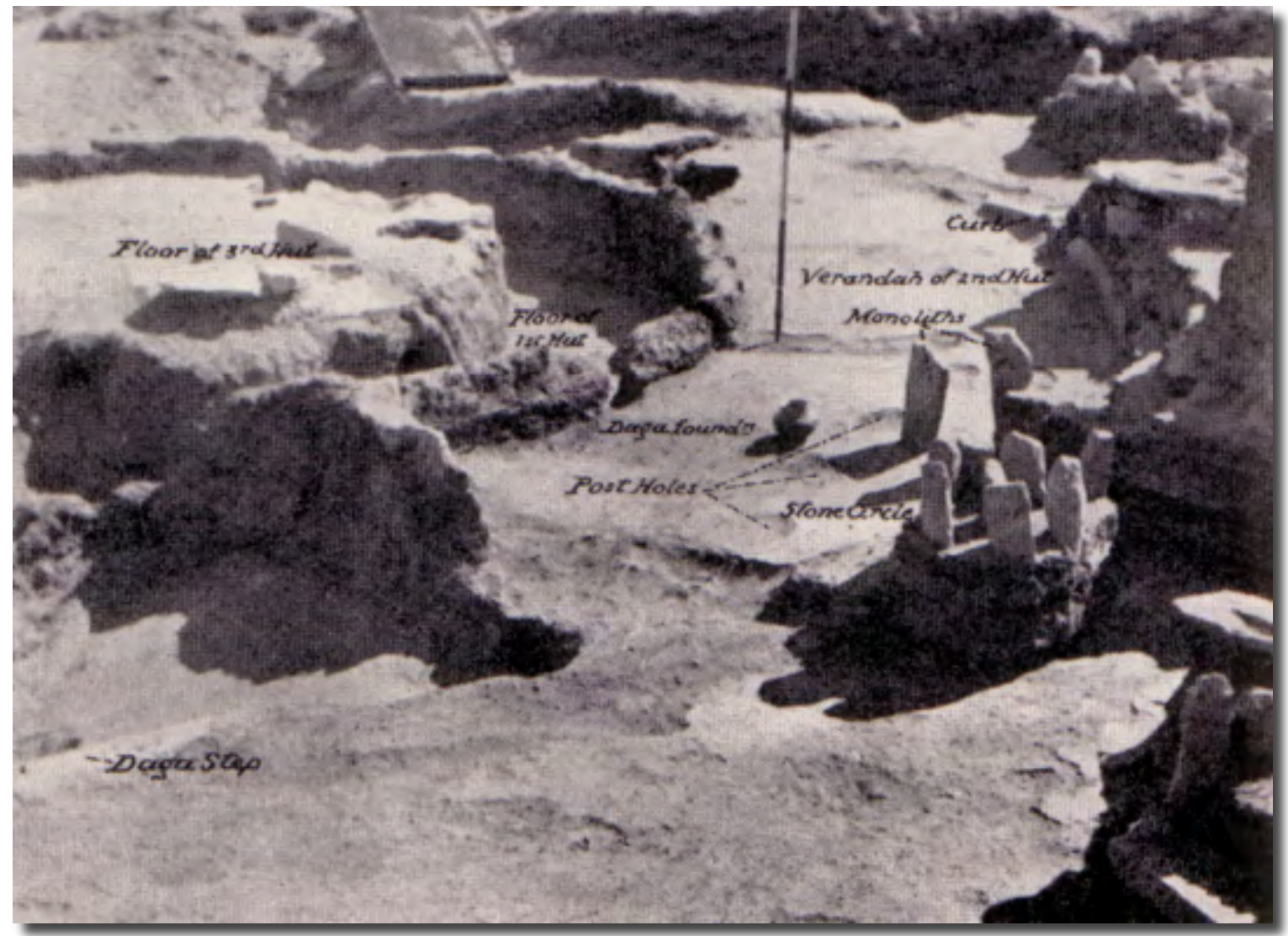

Figure 9. Architectural features in the Occupation Area exposed in Excavation JS 2(b) in 1934 (Fouché 1937:13; Plate VIII, 6), including the floor and wall base remains of a veranda type circular pole and daub structure, a stone circle consisting of stone columns in vertical position, and nearby small monoliths.

\section{Stone mortar blocks, mortar hollows and stone lined pits}

Sunken stone mortar blocks are typically positioned in small stone lined pits, often surrounded by or adjacent to gravel floors; as well as stone lined pits that may once have contained stone or wooden mortar blocks (cf. Figure 10; Table 3: "Sunken mortar block", and "mortar pit stone lining"). During earlier times the Vhavenda used a similar type of sunken cereal stamping block, mutuli, made of wood or stone, and that was embedded in the floor of the cooking hut, tshitanga (Van der Waal 1977; Tshikosi 2009). 


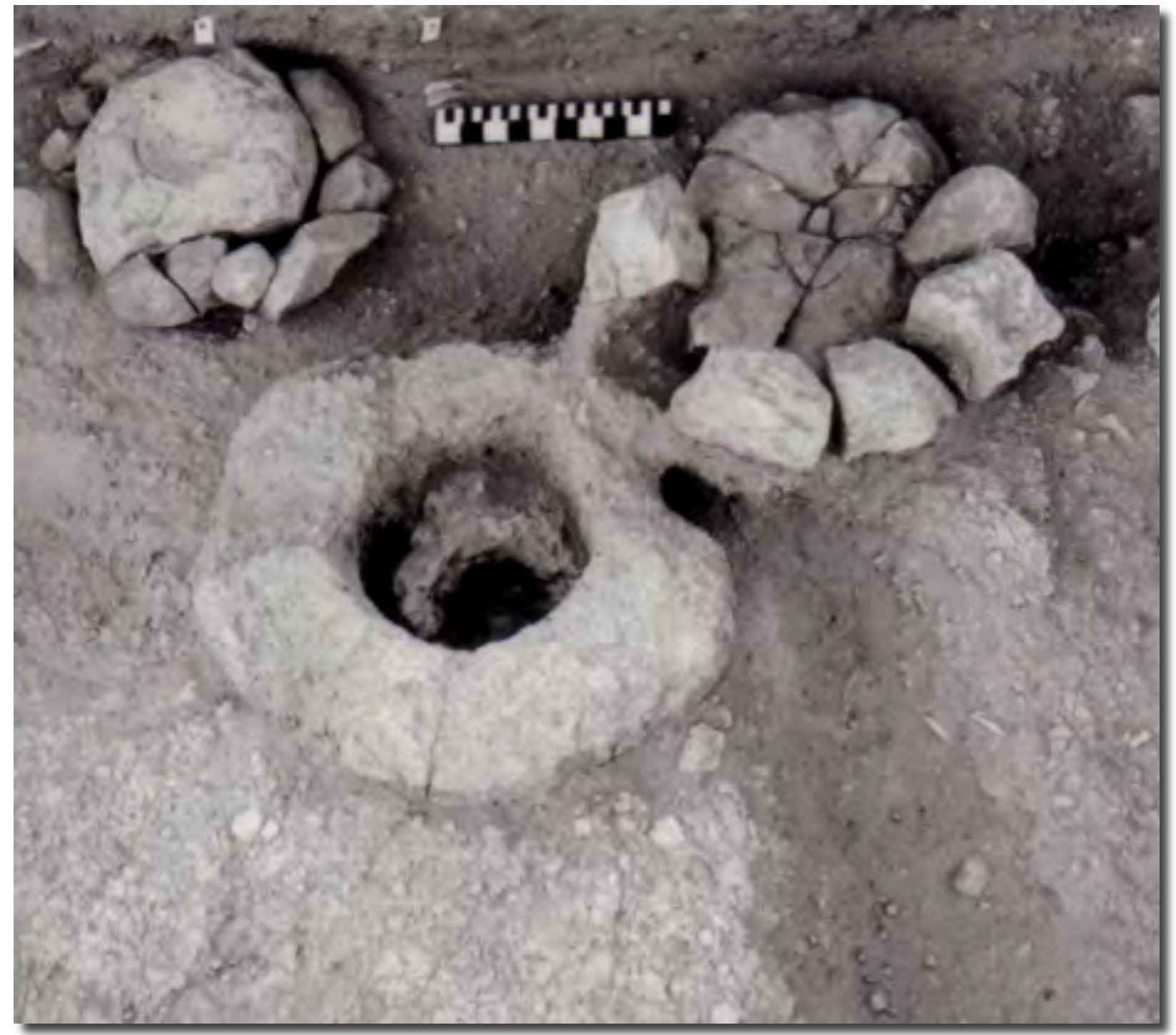

Figure 10. Sunken stone mortar blocks positioned in small, stone lined pits, exposed in Layer 9(i) in Excavation MK1 on Mapungubwe Hill. Note the clay rim surrounding the stamping hollow of the nearest mortar block that is embedded in a gravel floor; the sunken mortar block still mounted in the stone lined pit to the left at the back; and the stone lining including a cracked, flat bottom stone to the right at the back (cf. also Meyer 1998:123, Figure 3.57).

\section{Stone structures with sunken clay pots}

It is a large, storage type of ceramic vessel, found buried in possible association with vertically arranged stones (cf. Figure 11). Several large ceramic vessels were found in situ, embedded in the ground close to architectural structures elsewhere (Fouché 1937; Meyer 1979, 1998). 


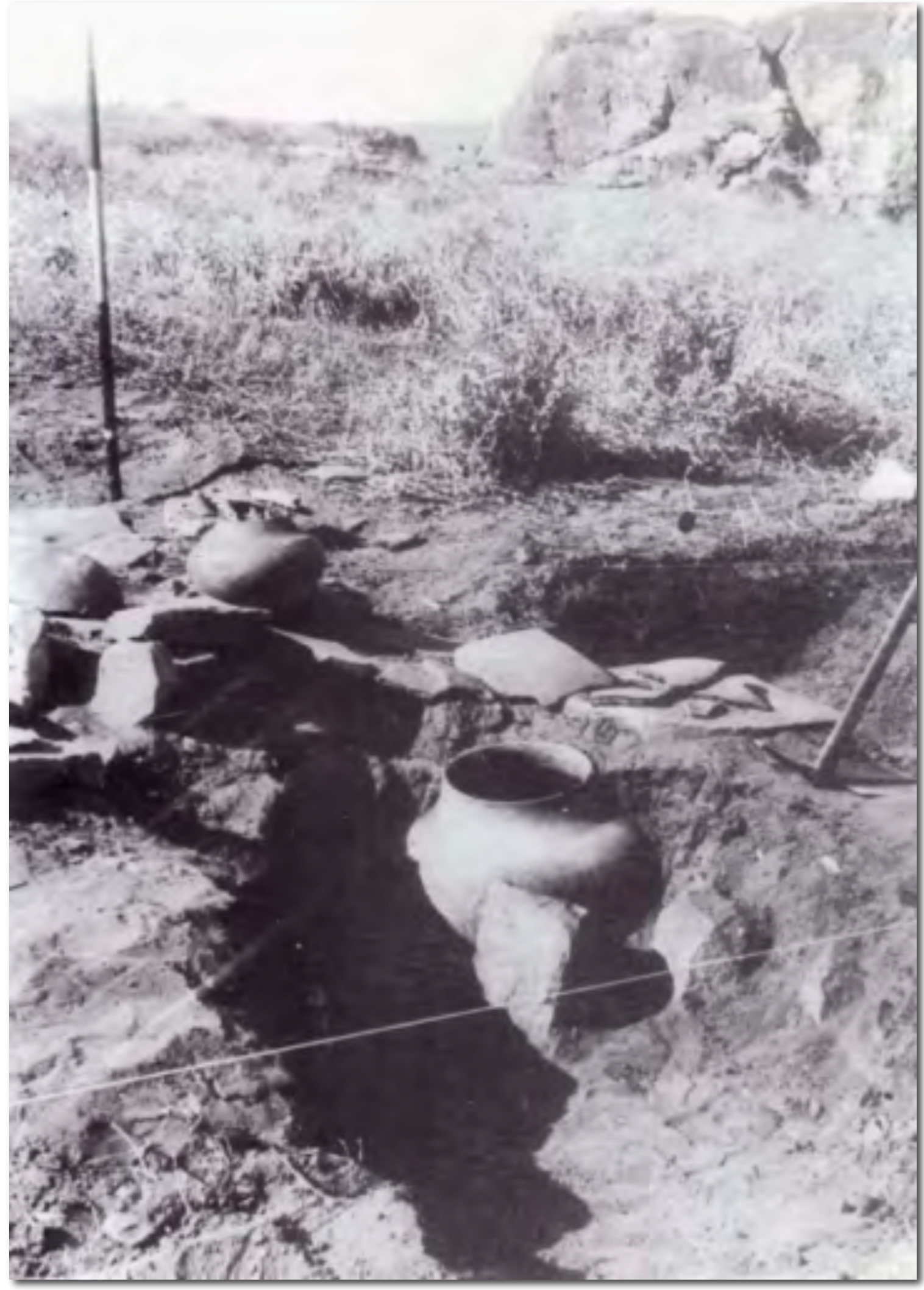

Figure 11. A large ceramic pot, apparently a storage vessel, sunken into the ground between or close to vertically positioned columnar stones, exposed during initial excavations on Mapungubwe Hill in 1933 or 1934 (Meyer 1998: 43). 


\section{Game hollows in stone}

Rows of hollows, usually consisting of sets of four rows with eight hollows each, are common features on the exposed sandstone surfaces of Mapungubwe Hill. At least two portable stones with sets of these game hollows were found on Mapungubwe Hill (cf. Figure 12). Similar game boards are used for games by the Bahananwa (Morata 2009) and the Vhavenda (Tshikosi 2009; Van der Waal 1977).

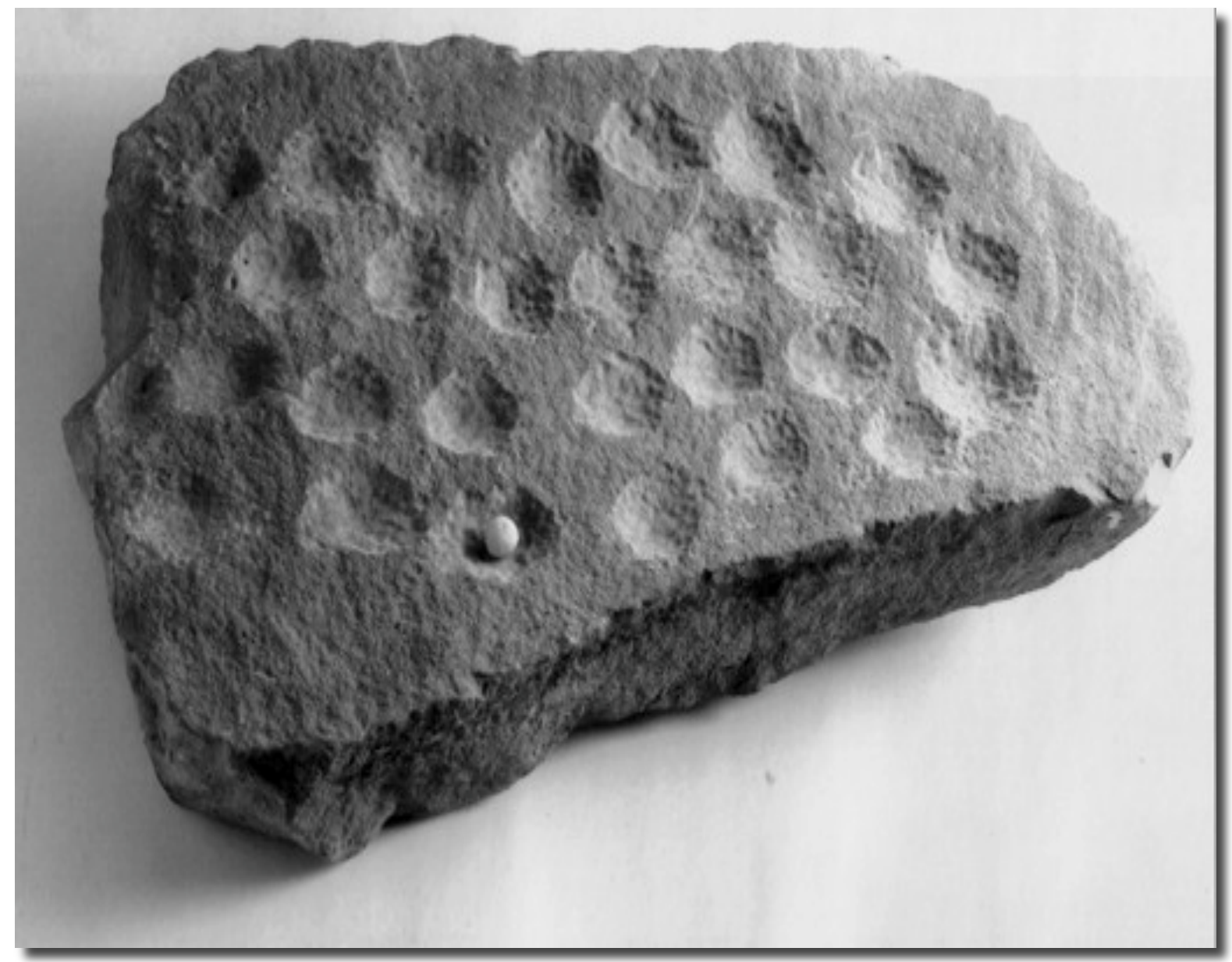

Figure 12. A portable stone game-board from Mapungubwe Hill, with a set of game hollows, consisting of four rows of six to eight hollows cut into the surface of a flat sandstone block. It is currently on display in the Mapungubwe Museum at the University of Pretoria.

\section{Climbing hollows}

Vertical sets of hollows, cut into the steep cliff access routes to the summit of Mapungubwe Hill, are interpreted as climbing hollows. In the case of the southern ascent to Mapungubwe Hill these hollows are thought to have possibly supported wooden steps inserted into the hollows (Fouché 1937).

\section{Circular pole and daub structures}

The wall base and floor remains of numerous circular pole and daub structures are typical of both Mapungubwe and K2 (cf. Fouché (1937); Gardner (1963); Meyer (1979; 1998). The remains of these structures consist of circular wall base trenches often containing embedded charred wooden post remains or post holes, or simply circular trenches or circular rows of post holes made into underlying deposits or in the rocky surface of Mapungubwe Hill. The hut structures vary from 
small, storage type structures to medium sized single-wall structures, and large double walled veranda type structures. Typical features of these structures are floors inside and around them, made of compacted sand or gravel. In layers of burnt hut rubble, many chunks of the sandy mud wall plaster still have post marks imprinted on them. In some cases the burnt wall clay rubble of small huts contains charred seeds of sorghum, millet and beans, evidence of the use of the huts as granaries. (Cf. Figure 12 to 15 ).

\section{Small circular pole and daub wall base without floor}

Small circular pole and daub hut type wall bases without compacted floors may have had raised wooden floors and were probably used as storage huts (cf. Figure 13; Table 2: "1. Small hut without floor"), similar to the typical Venda granary hut, dulu, that is traditionally built on a platform of stones and wood (Van der Waal 1977; Tshikosi 2009).

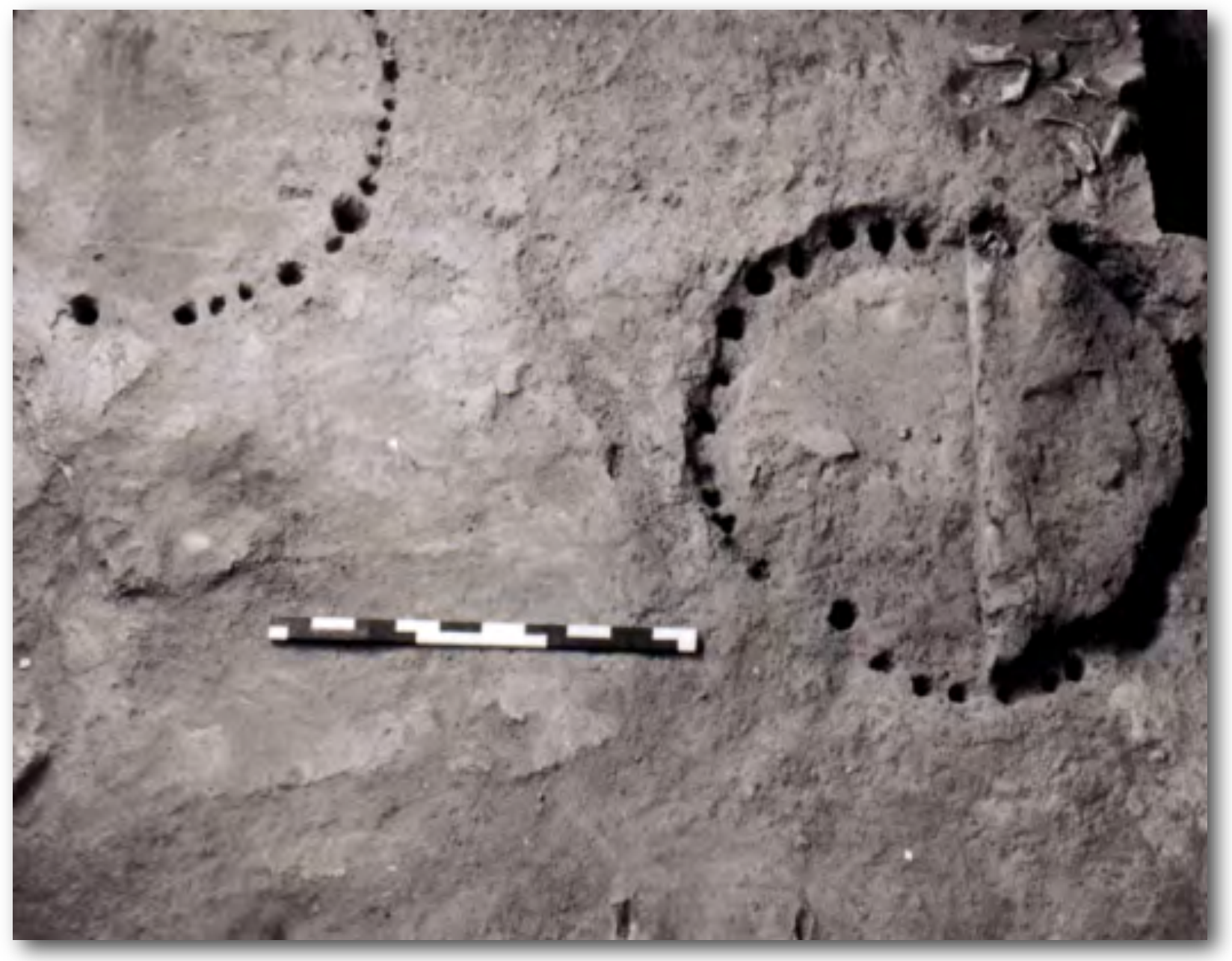

Figure 13. Two small circular pole and daub wall bases without floors in Layer 9(i) in Excavation F4 on the Southern Terrace at Mapungubwe (Meyer 1998:148, Figure 3.80).

\section{Small circular pole and daub hut wall bases with floors}

The remains of several circular pole and daub structures have floors made of compacted sand or gravel (cf. Figure 14; Table 2: "2. Small hut with floor"). 


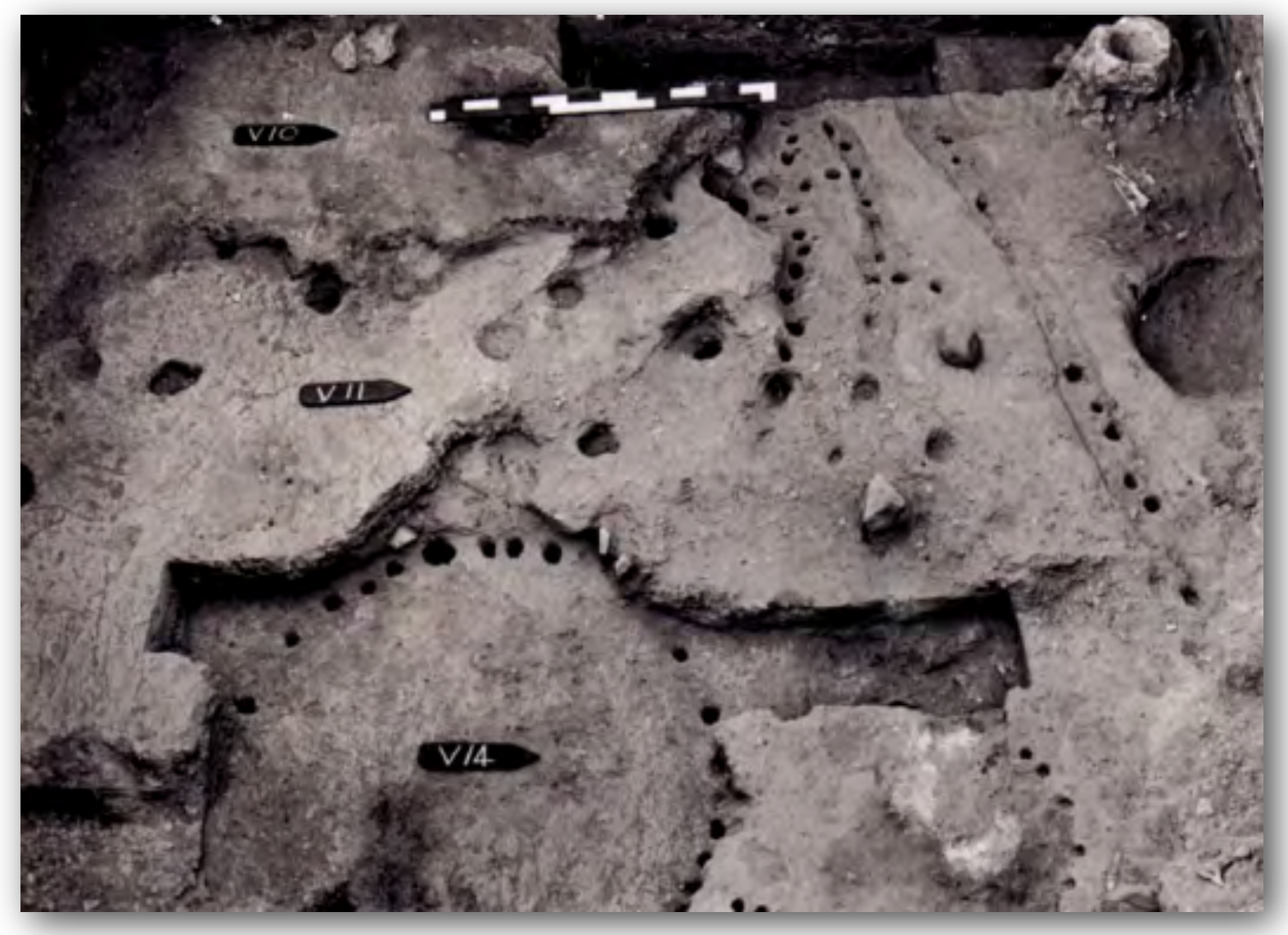

Figure 14. The circular row of wall post holes of a small hut enclosing a well compacted gravel floor, surrounded by a vertical sequence of outside or open-air gravel floors, situated adjacent to several parallel palisade type wall remains that consist of post holes in straight or slightly curved wall trenches (Meyer 1998:156, Figure 3.88).

\section{Medium sized single-wall bases with floors}

The remains of medium sized circular pole and daub type huts consist of floors made of compacted sand or gravel, surrounded by a single wall base trench, often with remains of posts or post holes (cf. Figure 15; Table 2: "3. Medium hut with floor"). 


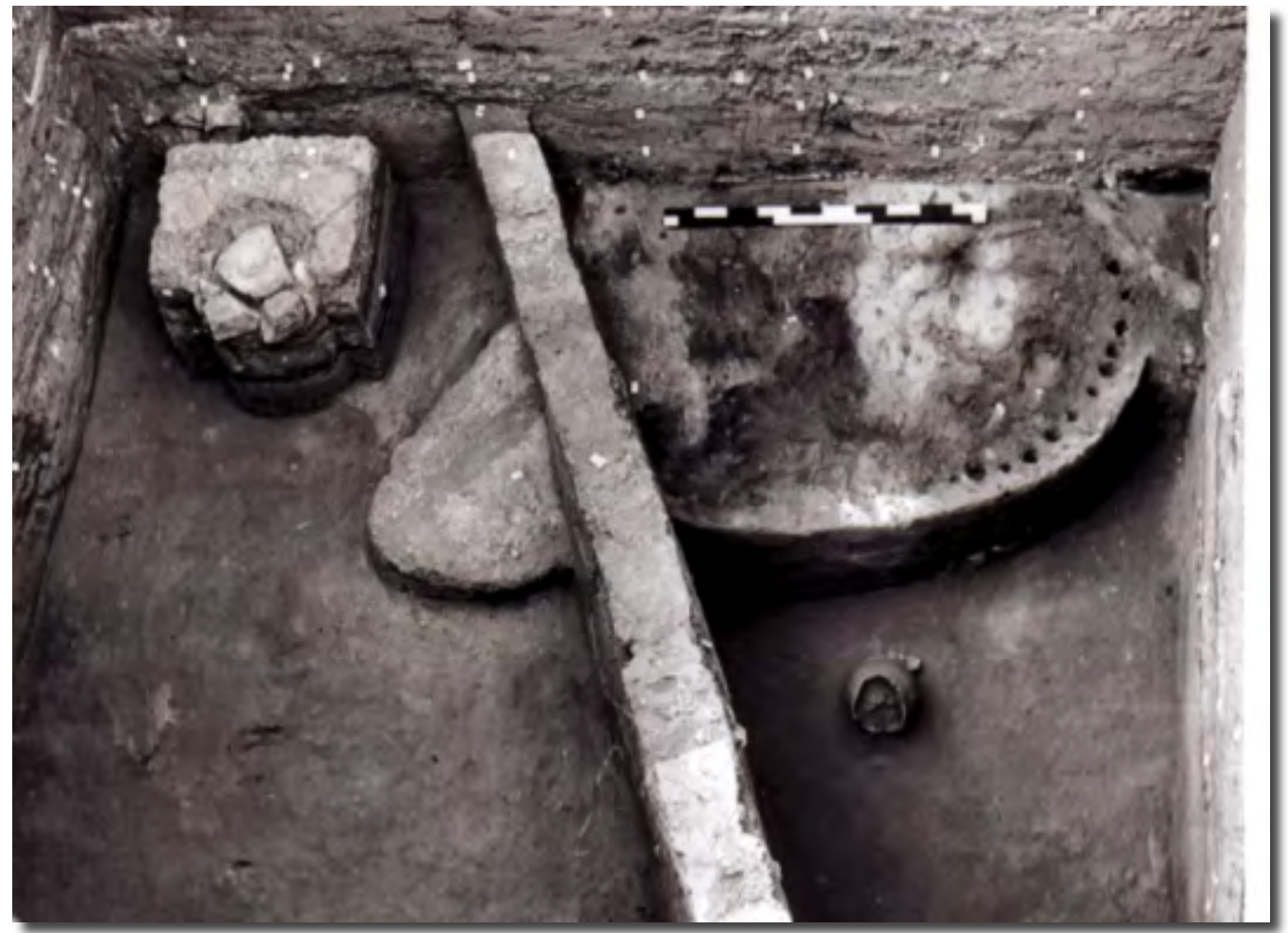

Figure 15. Excavation H5 on the Southern Terrace, showing an excavation witness section diagonally across the excavation; and remaining architectural remains of different layers left in situ, including a mortar stone in a stone-lined pit embedded in a gravel floor (to the rear left) in Layer 6(i), but probably belonging to Layer 5; a gravel patch in the middle; the remains of a medium-sized circular pole and daub structure (rear right) consisting of a compacted sand floor and a single row of wall post holes in a wall trench in Layer 6(iii); and a ceramic pot in a small pit in the sterile bottom deposit (Meyer 1998:157, Figure 3.90).

\section{Veranda type wall bases with floors}

The most prominent circular pole and daub structures are the remains of veranda type structures (cf. Figure 16; Table 2: "4. Veranda hut with wall posts", and "4. Veranda hut with wall trenches). These structures consist of two concentric, circular hut wall base trenches that are in some cases surrounded by a third wall or veranda base, sometimes with remains of a door entrance, or with a partition between the inner and outer wall. These structures were constructed with well compacted gravel floors, sometimes constructed with modelled hollows, steps and curbs (Fouché 1937:Plate VIII,6; Plate IX 2, 5; Diagram 4; Gardner 1963:Plate VIII; Meyer 1998: $83,124,155)$. In the traditions of the Vhavenda such a structure is the guvhagoha, a man's living or sleeping hut, constructed with storage space and in earlier times with a supported roof overhang or veranda, guda (Tshikosi 2009). 


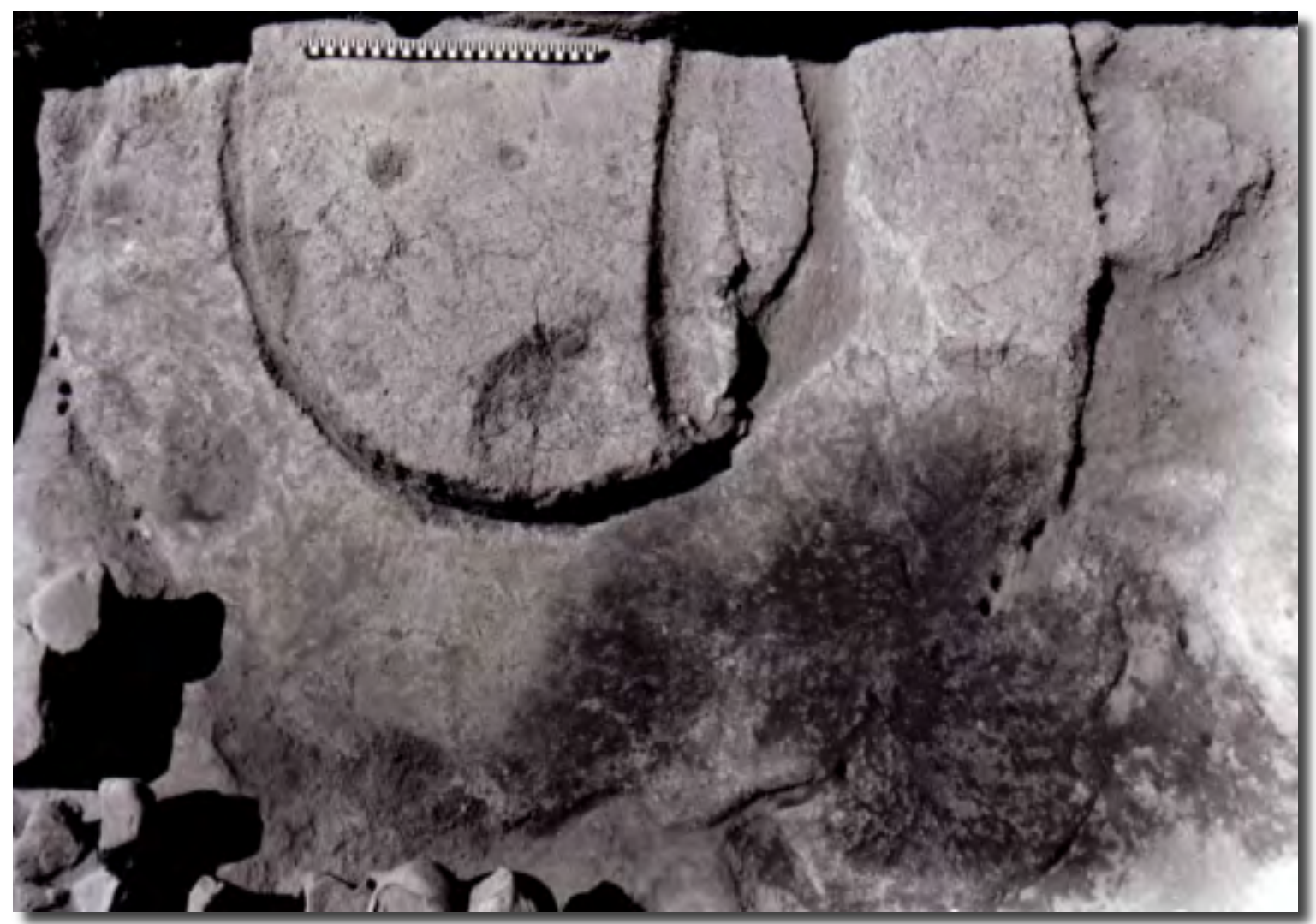

Figure 16. A veranda type circular pole and daub structure consisting of an inner wall, an outer wall, gravel floors with modelled hollows in the inner floor, and a doorway with a low step in the outer wall, in Excavation Ts 4, K2. (Meyer 1998:83, Figure 3.21, 3.27).

\section{Outside floors}

Outside floors are common on the sites and are often surrounding the circular pole and daub structures (cf. Figure 13). Their plan-forms are usually irregular and they are made of compacted gravel.

\section{Palisade wall bases}

Wall base remains of palisades (Figure 14) are in some cases present, typically close to or connected at right angles to circular pole and daub wall bases, often adjacent to or cutting through gravel floors (cf. Meyer 1998:137, 156).

\section{Kraals for domestic stock}

Concentrated dung deposits are believed to be evidence of domestic stock such as cattle, goats and sheep that were kept in wooden stockade type kraals for domestic stock, for example the large dung deposit on K2 (cf. Figure 17). Amongst the Vhavenda, cattle are kept in a stockade type kraal, danga, at night. Similar kraals are used by the Bahananwa. 


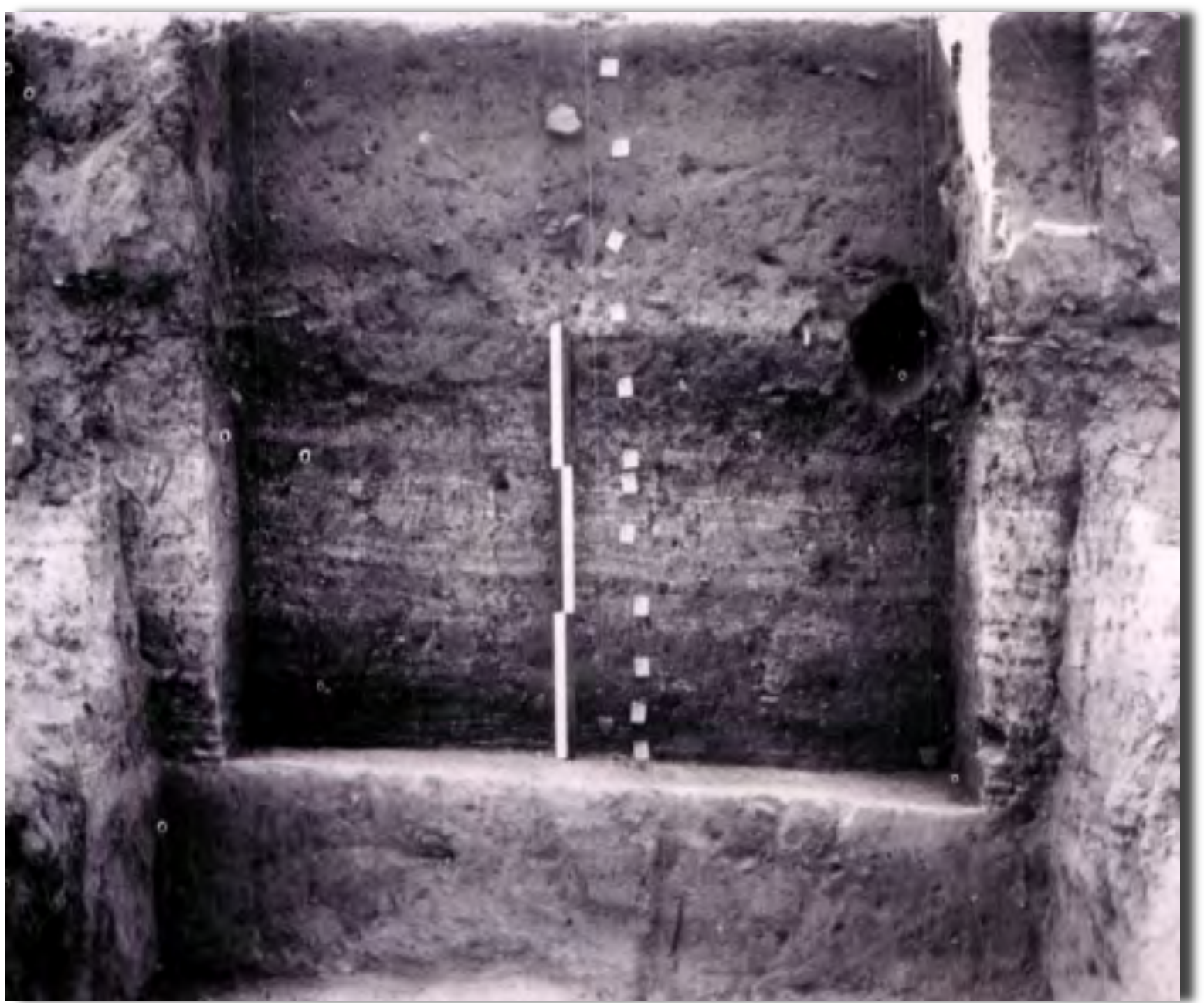

Figure 17. Excavation TS 1968 on K2, showing the dung deposit of the large kraal for domestic stock in the lower layers as indicated by the photographic scale marked in feet, covered by overlapping ash deposits of the large central midden on K2 (Meyer 1998:62, Figure 3.3).

\section{Gravel floors and stratigraphic context}

Numerous layers of gravel and compacted gravel floors served as outdoor living surfaces, often adjacent to circular pole and daub type hut structures, are typical site features on Mapungubwe and K2. They are frequently referred to by the authors of the field reports (cf. Figure 18). The gravel floors are important indicators of specific layers of occupation on the settlement sites. 


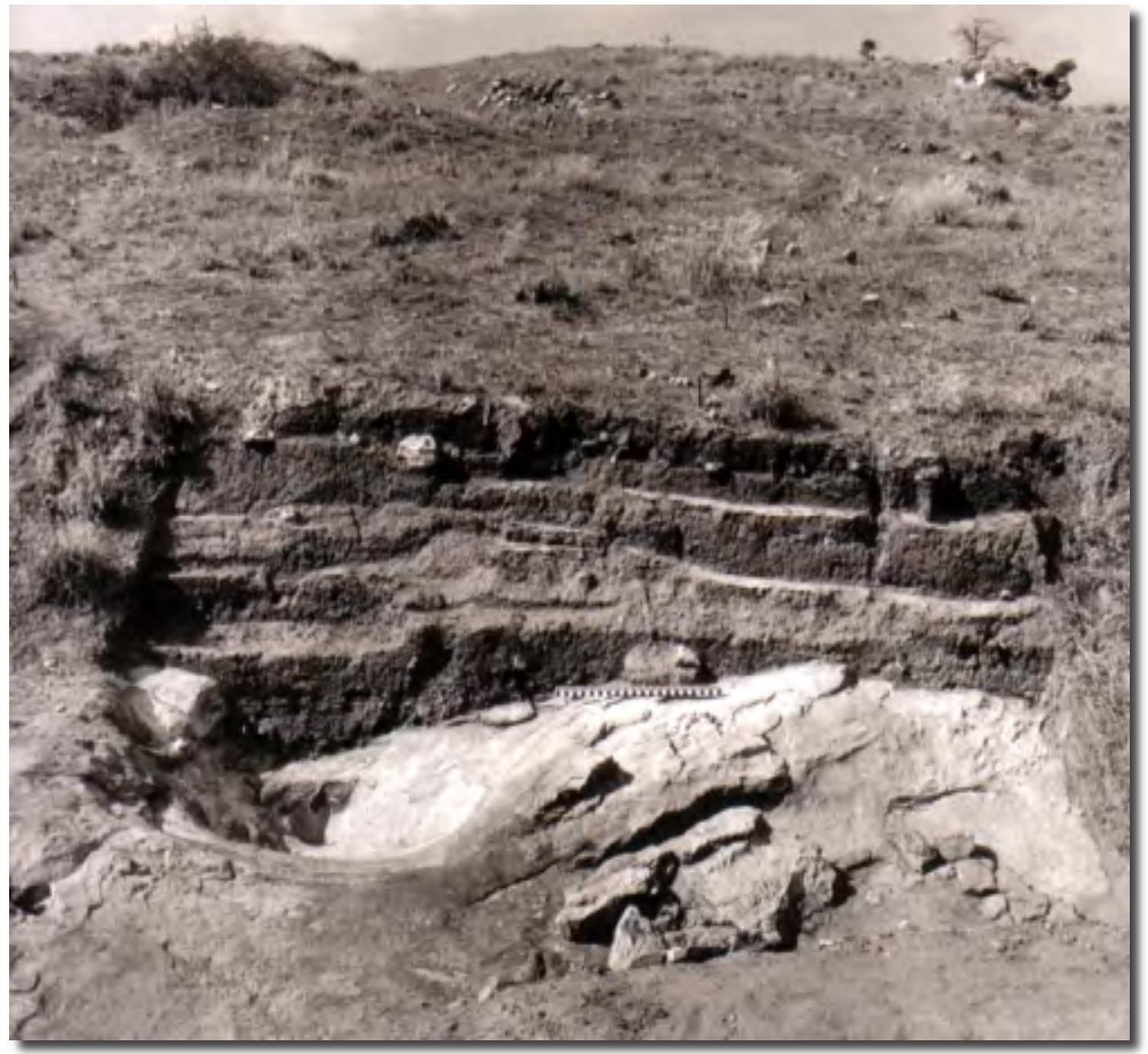

Figure 18. A vertical sequence of gravel floors visible in the wall profile of Excavation MK 3 in the deposits between the grave area and the terrace stonewall on Mapungubwe Hill, in 1973 (Meyer 1998: 139-141).

\section{Conclusions}

1. In the field reports of the exploratory and large scale excavations at Mapungubwe and K2 from 1933 to 1940 , relatively little information is available on the architecture of the sites. The only architectural features that were actually recorded during this period are those at Mapungubwe. The recorded single free-standing stonewalls, sections of terrace stonewalls and a small settlement complex consisting of the remains of an arrangement of circular pole and daub type structures and stone structures at Mapungubwe (Fouché (1937) and Jones (1937), however, seem to be representative of Mapungubwe architecture. Although these features were not directly dated, nor related to other site features in stratigraphic context and not compared with the ethnographic observations by Lestrade (1937) of traditional village architecture in the region at the time, and not interpreted as a functional village settlement unit, they are nevertheless a critically important record for the application of ethnographic analogy and settlement reconstruction. Gardner (1963) produced during his fieldwork a plan drawing that is a 
valuable record of a veranda type hut structure on Mapungubwe Hill. Gardner's interpretation of $\mathrm{K} 2$ as a Khoi settlement with late intrusions of different Bantu-speaking peoples was disproved by later research, and no significant archaeological records of the architecture of K2 were produced at this time. The methods and results of the research programme of the 1930s should, however, be understood against the relatively undeveloped scientific status of archaeology and anthropology as well as the particular trends in scientific theory at the time.

2. The more systematic stratigraphic reports of the excavations at Mapungubwe and K2 between 1950 and 1995 (Sentker 1969; Eloff 1979; Meyer 1979, 1998) contain numerous detailed descriptions of carefully excavated and recorded stone structures and the base remains of different circular pole and daub type structures in dated stratigraphic context, some of which are similar to those that had been uncovered earlier.

3. The above list of architectural structures and features is presented as a synthesis of relevant data from the different field reports in the archive; and provides an indication of the types of architectural structures of K2 and Mapungubwe. The stonewalls, stone platforms and sunken stone mortar blocks that appear to be particularly typical of the middle layers of Mapungubwe that are dated around AD 1220 to 1250. The circular pole and daub structures are typical of both Mapungubwe and K2, but small circular pole and daub granaries with compacted sand floors are particularly evident in layers of burnt hut rubble at K2. The architectural features together with associated artefact data and radiocarbon dates as related to the stratification of Mapungubwe and K2 during the various excavations should be fully integrated into a comparative diagram with the use of the Harris Matrix.

4. To date, the types of architectural structures and features in the sites were not reconstructed or interpreted in any of the field research reports, nor were they systematically compared to similar, traditional architecture of living communities in the region for the purposes of reconstruction and interpretation for presentations in publications, or in educational or museum displays.

5. The cultural objects and materials found in stratigraphic context with the architectural remains of Mapungubwe and K2 indicate that the inhabitants of these settlements practised an agro-pastoral economy and associated artefact technology that are relatively comparable to the subsistence and settlement traditions of existing Sotho and Venda speaking communities in the region. In spite of the time lapse of approximately seven hundred years between the settlement of Mapungubwe and the current kingdoms in the Limpopo region, and in spite of the diversity of languages spoken in the region, the apparent similarities between some observed tangible aspects of their cultural traditions and that of the inhabitants of Mapungubwe and K2 can be useful for the application of ethnographic analogy for the reconstruction of the architectural traditions of the past millennium in the area.

6. A relevant further research theme within the current project will be a systematic ethnoarchaeological comparison of the architectural remains of Mapungubwe and K2 with the traditional architecture of traditional communities with comparable socio-economic systems, within the contexts of their settlement traditions and construction economics and in interaction with their surrounding natural landscapes. 


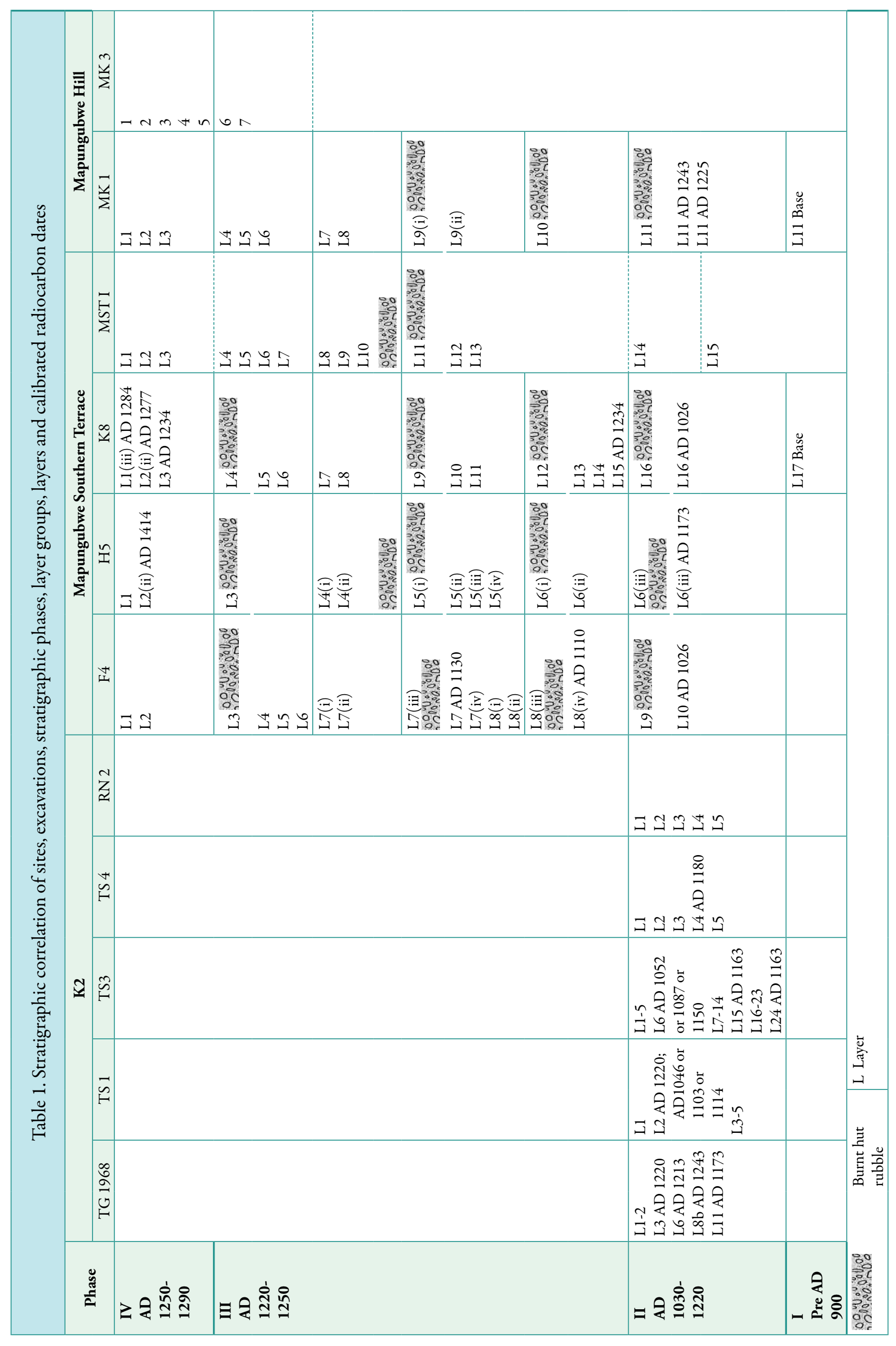




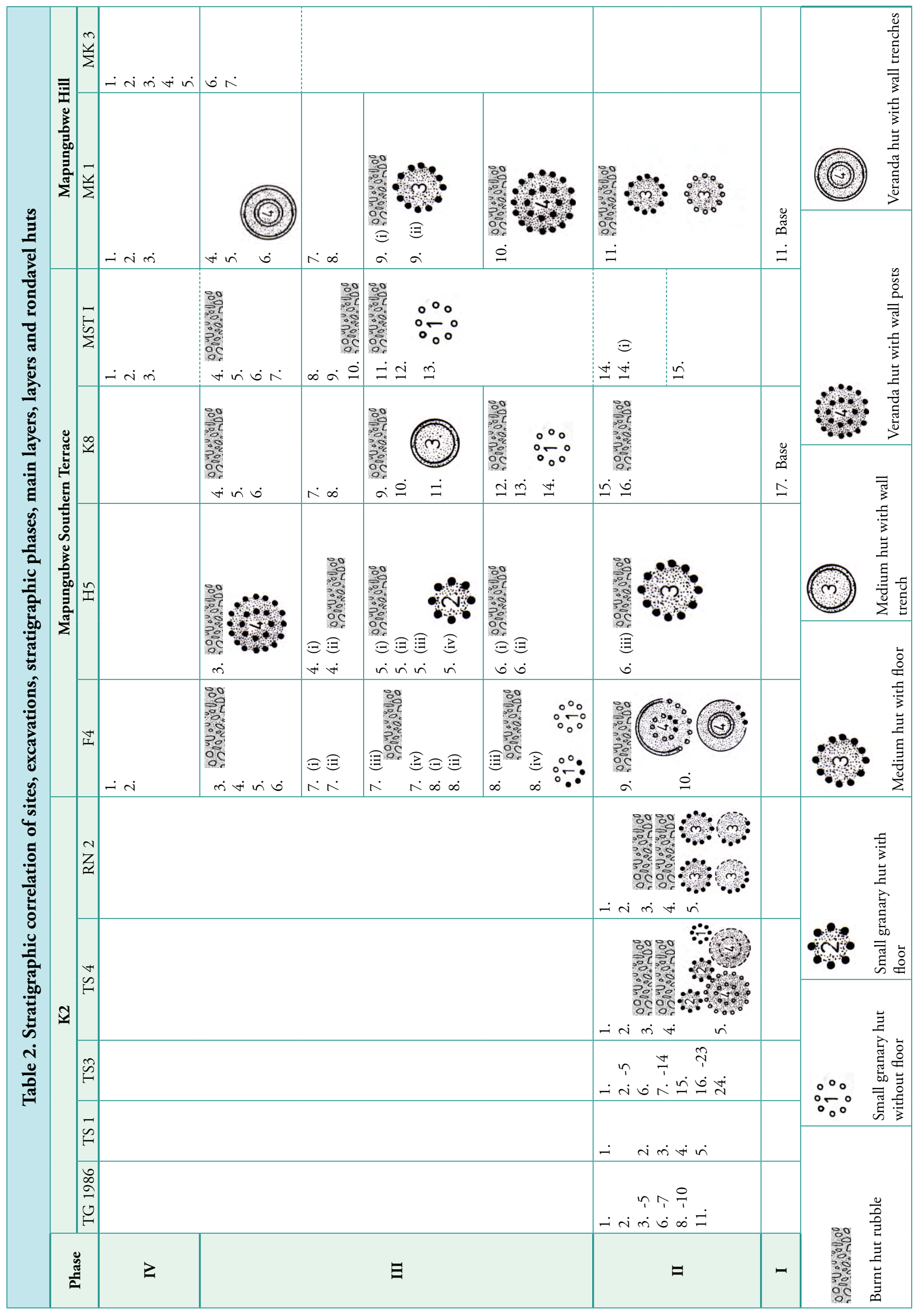




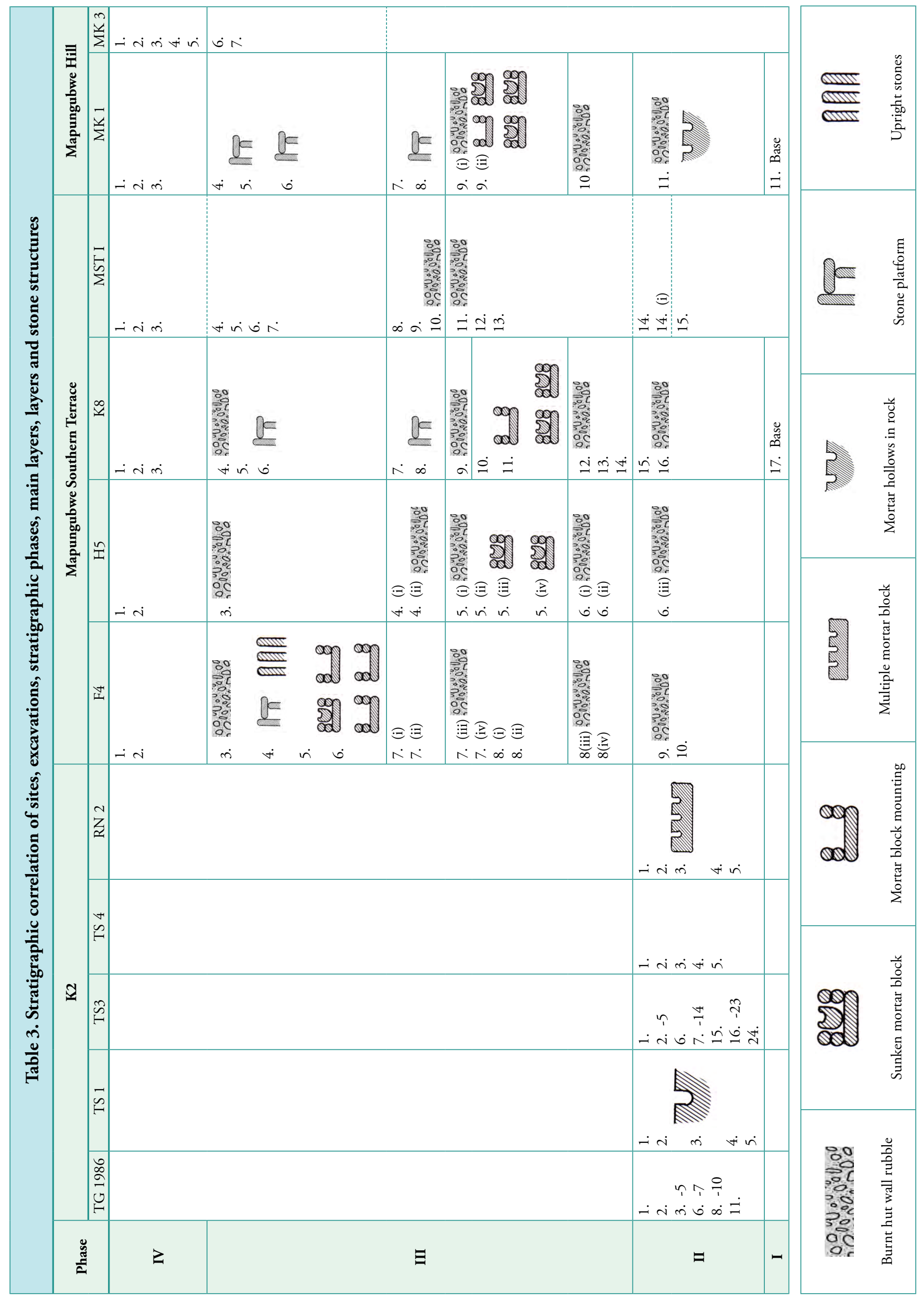




\section{Aknowledgements}

The following are credited and thanked for research and administrative support:

Department of Construction Economics, University of Pretoria.

Department of UP Arts and the Mapungubwe Museum and Archive, University of Pretoria.

Kgosi T. J. Maleboho; Mr. P. Morata, Chairperson of the Blouberg Tourism Association and Manager of Development in the office of Kgosi Maleboho; and the BaHananwa Royal Council.

Thovhele M.P.K. Tshivhase and the Tshivhase royal family; and Mr. G. Tshikosi, spokesperson of Thovhele Tshivhase.

\section{References}

Denyer, S.1978. African traditional architecture. London: Heinemann

Eloff, J.F. 1979. Die kulture van Greefswald. Volume 1-5. Universiteit van Pretoria: Ongepubliseerde verslag aan the Raad vir Geesteswetenskaplike Navorsing.

Fouché, L. (ed.) 1937. Mapungubwe: ancient Bantu civilization on the Limpopo. Cambridge: Cambridge University Press.

Galloway, A. 1937. 'The skeletal remains of Mapungubwe'. In: Fouché, L. (ed) Mapungubwe: ancient Bantu civilization on the Limpopo: 127-174. Cambridge: Cambridge University Press.

Galloway, A. 1959.The skeletal remains of Bambandyanalo. Johannesburg: Witwatersrand University Press.

Gardner, G.A. 1955. Mapungubwe 1935-1940. South African Archaeological Bulletin 10: $73-77$.

Gardner, G.A. 1956. 'Mapungubwe and Bambandyanalo'. South African Archaeological Bulletin 11: 55-56.

Gardner, G.A. 1963. Mapungubwe Vol. 2. Pretoria: J.L. van Schaik.

Guidoni, E. 1987. Primitive architecture. New York: Rizzoli.

Hole, F. and Heizer R.F. 1973.An introduction to prehistoric archeology. New York: Holt, Rinehart and Winston. $3^{\text {rd }}$ Edition.

Jones, N. 1937. 'The 1934 expedition’. In: Fouche, L. (ed.) Mapungubwe: ancient Bantu civilization on the Limpopo. Cambridge: Cambridge University Press.

Lestrade, G.P. 1937. 'Report on certain ethnological investigations in connection with the archaeological discoveries at Mapungubwe'. In: Fouche, L. (ed.) Mapungubwe: ancient Bantu civilization on the Limpopo. Cambridge: Cambridge University Press. 
Maleboho, T.J. 2009. Personal comment. Blouberg, Limpopo Province, South Africa.

Meyer, A. 1979. 'Stratigrafie van die Greefswaldterreine'. In: Eloff, J.F. 1979. Die kulture van Greefswald. Deel 1, 4, 5. Universiteit van Pretoria: Ongepubliseerde verslag aan the Raad vir Geesteswetenskaplike Navorsing.

Meyer, A. 1998.The Iron Age sites of Greefswald: Stratigraphy and chronology of the sites and a history of investigations. Pretoria: University of Pretoria.

Meyer, A. 2007. 'A king behind a stone wall? A synthesis of architecture, artefacts and social memories'. Shashe-Limpopo Research Symposium, University of Pretoria, 26 - 27 September.

Morata, P. 2009. Personal comment. Blouberg, Limpopo Province, South Africa.

Pikirayi, I. 2001. The Zimbabwe Culture. Oxford: Rowman and Littlefield Publishers.

Schoeman, M. H. 2006. 'Imagining Rain-Places: Rain-Control and Changing Ritual Landscapes in the Shashe-Limpopo Confluence Area, South Africa'. The South African Archaeological Bulletin, Vol. 61, No. 184 (Dec.), pp. 152-165.

Sentker, H.F. 1969. 'Mapungubwe 1953 - 1954'. Ongepubliseerde verslag. Pretoria: Universiteit van Pretoria.

Sinclair, P. 2007. Personal comment. Department of Archaeology and Ancient History, Uppsala University.

Summers, R. 1971. Ancient ruins and vanished civilizations of southern Afdrica. Cape Town: T.V. Bulpin.

Tosh, J. 2006. The pursuit of history. Harlow, England: Pearson. Fourth Edition.

Tshikosi, G. 2009. Personal comment. Sibasa, Limpopo Province, South Africa.

Van der Waal, C.S. 1977. Die woning en woonwyse onder die Venda. Ongepubliseerde Magisterverhandeling, Universiteit van Pretoria.

Van Riet Lowe, C. 1933. 'Mapungubwe contoured plan of summit'. Unpublished map, Mapungubwe Archive, University of Pretoria.

Vansina, J. 1997. Oral Tradition as history. Oxford: James Currey. Reprint of first edition 1985.

Vogel , J.C. 1998. 'Radiocarbon dating of the Iron Age sites on Greefswald'. In: Meyer, A. 1998. The Iron Age sites of Greefswald: Stratigraphy and chronology of the sites and a history of investigations. Pretoria: University of Pretoria. 